\title{
Strength Evaluation of Connectors for Intermodal Containers
}

H. S. Lew

Fahim Sadek

Erik D. Anderson

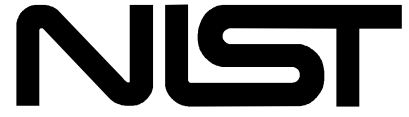

United States Department of Commerce Technology Administration

National Institute of Standards and Technology

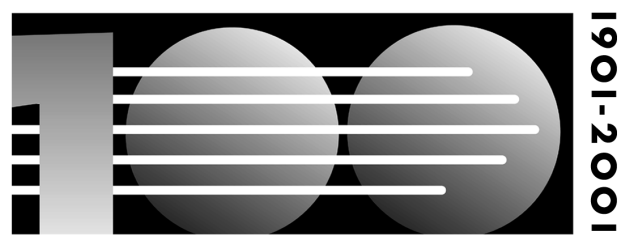

N I S T C E N T E N N I A L 


\section{Strength Evaluation of Connectors for Intermodal Containers}

H. S. Lew

Fahim Sadek

Erik D. Anderson

Building and Fire Research Laboratory

National Institute of Standards and Technology

Gaithersburg, MD 20899

Prepared for

Office of Maritime Safety Standards

Occupational Safety and Health Administration

Department of Labor

August 2000

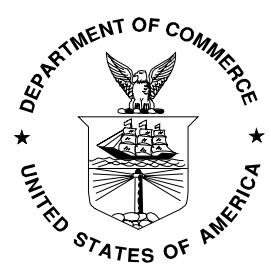

U.S. Department of Commerce

Norman Y. Mineta, Secretary

Technology Administration

Dr. Cheryl L. Shavers, Under Secretary of Commerce for Technology

National Institute of Standards and Technology

Raymond G. Kammer, Director 


\section{PREFACE}

This report presents the results of an experimental study of semi-automatic twistlocks and latch locks that are used to interconnect marine cargo containers. Although these interbox connectors are primarily used to secure containers during shipping, they are also used in lifting two empty containers, one on top of the other. In this process, known as vertical tandem lift (VTL), the bottom container's weight is transmitted to the upper container by means of the interbox connectors. The Occupational Safety and Health Administration (OSHA), the Department of Labor, is concerned with the safety of workers during a VTL where disengagement or failure of one or more connectors could create a hazardous condition. Under an interagency agreement with OSHA, the National Institute of Standards and Technology (NIST), the Department of Commerce, carried out an experimental program to assess the load carrying capacity of interbox connectors. Mr. Paul Rossi of the Office of Maritime Safety Standards of OSHA provided technical guidance throughout the study.

Any opinions, findings, conclusions and recommendations expressed in this report are those of the authors and do not necessarily reflect the views of NIST or OSHA.

Certain trade names and company products are mentioned in the text or identified in illustrations in order to adequately describe test specimens. In no case does such identification imply recommendation or endorsement by NIST and by OSHA, nor does it imply that the products are necessarily the best available for the purpose. 


\begin{abstract}
Intermodal containers are used widely in marine cargo handling. In order to facilitate unloading of empty containers from ship to shore, two containers are frequently lifted in tandem. This operation is referred to as "vertical tandem lifting." In this lifting process, the lower container is attached to the upper container by means of interbox connectors at the four corners of the container. During the vertical tandem lifting operation, if one or more connectors are disengaged, the bottom container may be separated from the upper container, thereby creating an unsafe condition to workers below. This safety concern prompted the Occupational Safety and Health Administration (OSHA) to request the National Institute of Standards and Technology (NIST) to study the suitability of interbox connectors for vertical tandem lifting.

The NIST study included site visits to port facilities and laboratory tests of interbox connectors. Test specimens included semi-automatic twistlocks and latch locks. The experimental program included testing of twistlocks in tension, twistlock and latch lock assemblies with corner fittings in tension and compression, and shafts of twistlocks in tension to obtain the stress-strain relationship. In addition, measurements were made of the bearing area of the top and bottom cones of twistlocks and the latch on the inner surface of the corner fitting.

The study indicated that the tensile capacity of the connection is governed by the strength of the corner fitting. The study also shows that the bearing area of latch locks on the corner fitting is less than that required by the ISO standards.
\end{abstract}

Keywords: container; corner fittings; interbox connectors; latch locks; twistlocks; vertical tandem lifts. 


\section{TABLE OF CONTENTS}

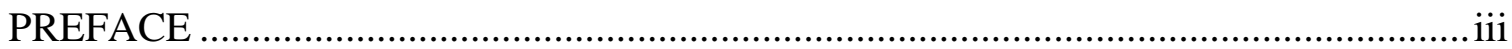

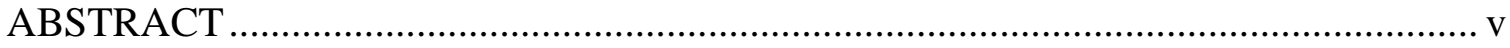

TABLE OF CONTENTS ..................................................................................... vii

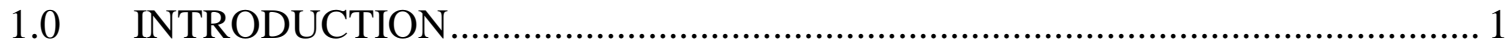

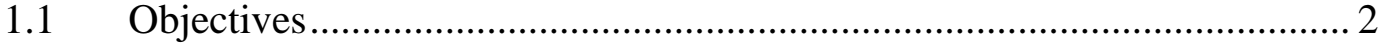

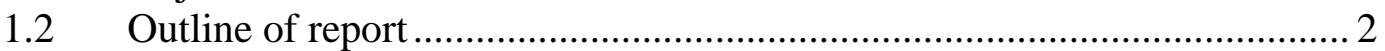

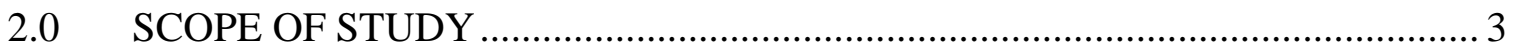

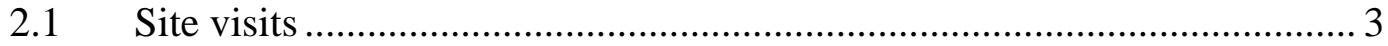

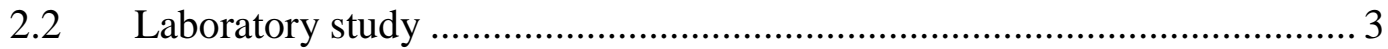

3.0 DESCRIPTION OF TEST SPECIMENS ………….................................. 5

3.1 Specimen identification................................................................ 6

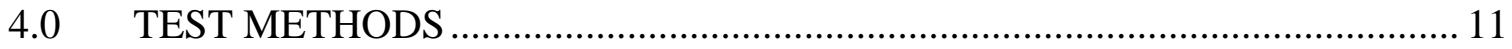

$4.1 \quad$ Tension capacity of twistlocks ............................................................... 11

4.2 Tension capacity of twistlock and latch lock assemblies .......................... 11

4.3 Compression capacity of twistlock and latch lock assemblies.................. 12

4.4 Tensile strength of twistlock shaft materials ............................................. 12

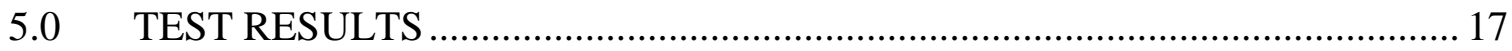

5.1 Tension capacity of twistlock shafts ................................................. 17

5.2 Tension capacity of twistlock and latch lock assemblies ........................ 17

5.3 Compression capacity of twistlock and latch lock assemblies................. 18

5.4 Tensile strength of twistlock shafts ...................................................... 19

5.5 Measurement of load bearing areas..................................................... 19

6.0 CONCLUSIONS AND RECOMMENDATIONS............................................... 35

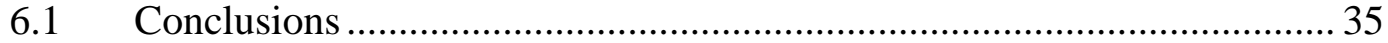

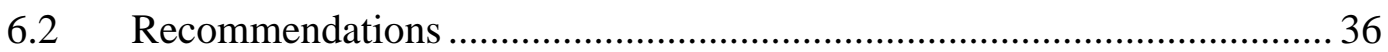

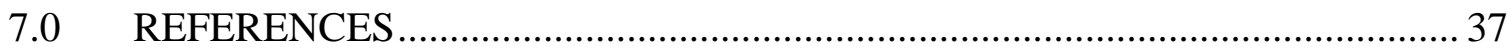




\section{$1.0 \quad$ INTRODUCTION}

Intermodal containers are widely used in marine cargo handling. The containers are usually stacked more than four tiers high on the ship deck during sea transport. To secure containers to the ship deck during transportation, they are interconnected by interbox connectors. In addition, diagonal bracings are used for the lower two tiers of interconnected containers to provide lateral stability against racking. When empty containers are unloaded from ship to shore, two containers are frequently lifted in tandem, one on top of the other. This operation is referred to as "vertical tandem lift (VTL)." In this lifting process, the weight of the lower container is transmitted to the upper container by means of the interbox connectors at the four corners. Thus, the upper container and connectors together become a lifting device for the lower container.

In general, an intermodal container is comprised of four parts. They are: (1) a boxshaped steel frame including four corner posts and corner fittings (or corner castings), which are welded to the top and bottom of the four corner posts; (2) end and side walls; (3) a door opening at one end; and (4) floor and roof. The connectors are engaged directly into the corner fittings, and thus, all lifting loads are transferred to the corner posts through the corner fittings.

Newly manufactured containers are designed, constructed, and tested according to standards promulgated by the International Organization for Standardization (ISO). The relevant ISO standards are ISO 1161, the general specification for corner fittings [1] and ISO 1496, the standard for design and testing of containers [2]. Because all corner fittings are manufactured according to the ISO standard, connectors of all types fit into the corner fittings.

The shipping industry uses a variety of interbox connectors, broadly grouped into four categories: (1) conventional twistlocks; (2) semi-automatic twistlocks; (3) fully automatic twistlocks; and (4) latch locks. The primary components of these connectors are made of either forged or cast steel. Although the locking mechanisms of twistlocks and latch locks differ, they all function the same way. They lock into the corner fittings of the top and bottom containers, thereby interconnecting them.

During the vertical tandem lifting operation, if one or more connectors are disengaged from corner fittings, the bottom box may be separated partially or totally from the upper container, thereby creating an unsafe condition for workers below. This safety concern prompted the Occupational Safety and Health Administration (OSHA) to request the National Institute of Standards and Technology (NIST) to study the structural performance of interbox connectors.

At present, there is no standard for design, manufacturing, testing, or use of interbox connectors in lifting operations. The manufacturers of such connectors provide information on the tensile and shear strengths and safe-working capacities of new 
connectors based on their test data. Without a testing standard to follow, it is expected that disparities exist in manufacturers' test data.

In the course of many repeated uses, connectors may sustain varying degrees of damage due to overstressing and corrosion. No systematic investigation has been carried out to determine whether there is a significant strength reduction or malfunctioning of connectors with use. Thus, it is not possible at present to establish safe working strengths of connectors relative to their use history and age. In absence of the strength data of connectors in service, no guidelines have been established to modify the safe working strength of connectors as a function of their use history and age.

For this study, OSHA selected semi-automatic twistlocks and latch locks for strength evaluation. The semi-automatic twistlocks were selected because of their wide use while the latch locks were chosen because of their unique operational feature.

\subsection{Objectives}

The objectives of this experimental study were to (1) assess the load capacity of selected semi-automatic interbox connectors in tension and compression, and thereby assess their suitability for vertical tandem lifts, and (2) identify the weakest link in the connectorcorner fitting assembly.

\subsection{Outline of report}

The report is organized into seven sections. Section 2 describes the scope of the study. Section 3 presents the description of the twistlocks and latch locks that were tested. Section 4 describes the test methods and fixtures used for each type of loading. Section 5 presents the results of the tests and other pertinent measurements. Section 6 provides the conclusions and recommendations from this study. Section 7 lists the references cited in the report.

Tables and figures are contained at the end of each section. Tables and figures are numbered by section and by order of occurrence within the section. 


\subsection{SCOPE OF STUDY}

This study included (1) site visits to view loading and unloading operations of containers, and (2) laboratory tests of both new and used twistlocks and latch locks.

The study focused on testing selected types of interbox connectors that included twistlocks and latch locks. The results presented in this report should not be extrapolated to other types of connectors not included in this study. During the course of this study, no attempt was made to conduct a statistically rigorous testing program, but only to assess in broad terms the structural performance of the connectors and identify their failure mechanism and the weakest link. The objective of this study was not to qualify or disqualify a certain product or to suggest preference of one product over another.

The study was limited to investigating interbox connectors and connector-corner fitting assemblies. No attention was given to the overall structural integrity of the container. For example, the welded connection between the corner fitting and the corner post may present a weaker connection than the interbox connector-corner fitting assembly. Further studies are required to address this issue.

\section{$2.1 \quad$ Site visits}

Prior to initiating the laboratory study, port facilities in Baltimore, Maryland and Hampton, Virginia were visited.

At the port of Baltimore, a demonstration was made using a gantry crane to simulate vertical tandem lifts (Fig. 2.1), and to show how the sway motion is imparted to the containers due to sudden stopping of the gantry crane (Fig. 2.2). When the containers are blocked by a fixed object, the sway motion may cause shear force in the connectors. At the port of Hampton, actual operations of unloading of containers from ship to shore were viewed.

\subsection{Laboratory study}

Four different load tests were performed. These included:

- Tension capacity of twistlocks,

- Tension capacity of twistlock and latch lock assemblies with corner fittings,

- Compression capacity of twistlock and latch lock assemblies with corner fittings, and

- Tensile strength of twistlock shaft materials.

In addition, measurements were made of the bearing area of the top and bottom cones of twistlocks and the latch of latch locks on the inner surface of the corner fitting. 


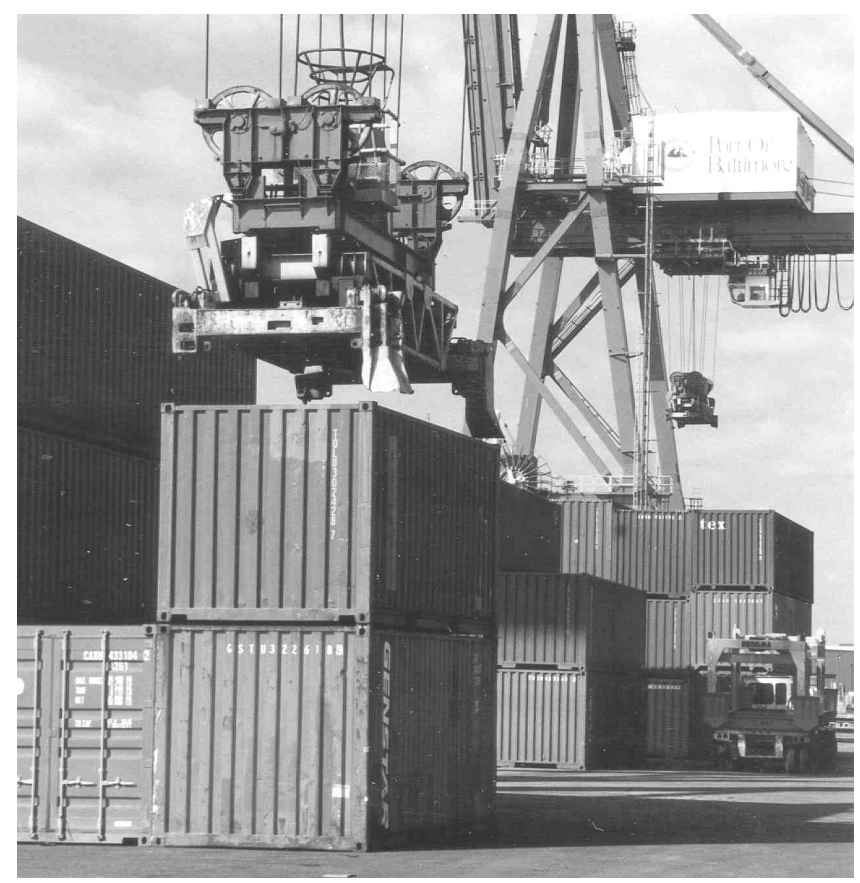

Figure 2.1 Lifting of Containers by Gantry Crane

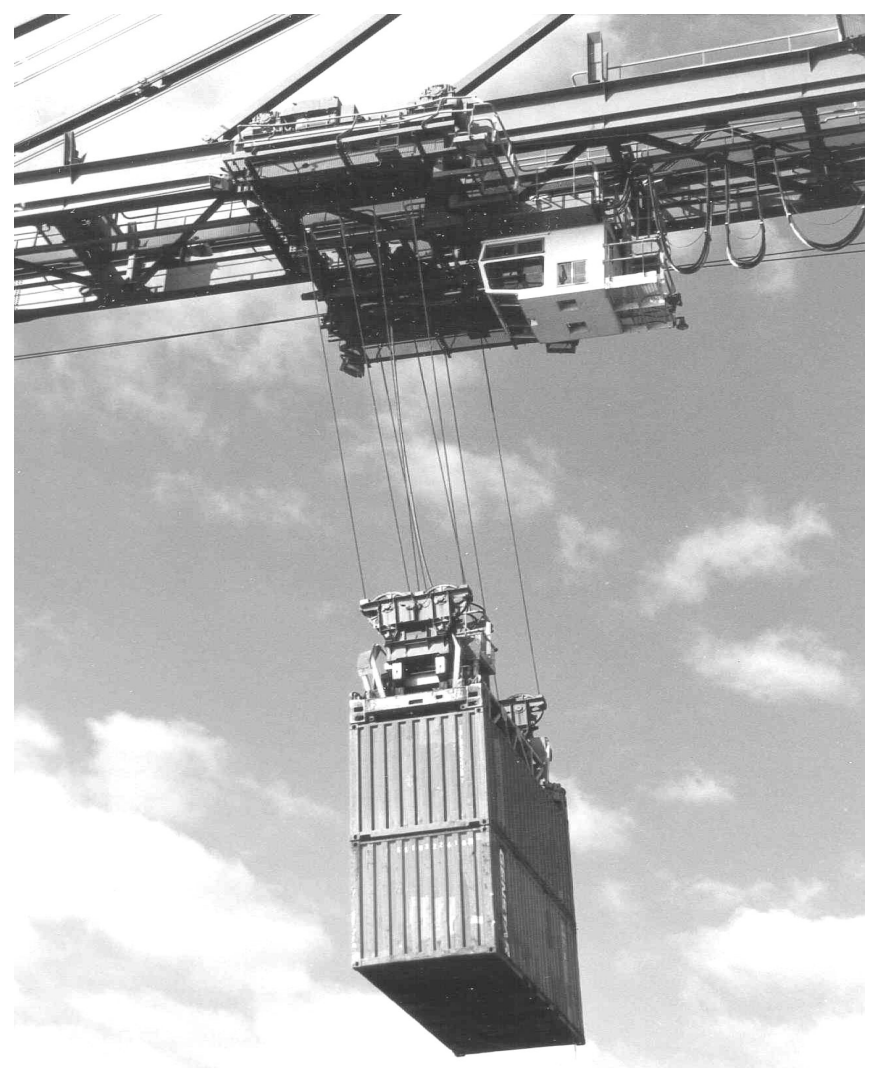

Figure 2.2 Sway Motion of Containers 


\subsection{DESCRIPTION OF TEST SPECIMENS}

Semi-automatic twistlocks are manufactured worldwide. At the time of this study, about twelve manufacturers produced most of the twistlocks used by the shipping industry. They are manufactured in Australia, Denmark, Germany, Japan, Sweden and the United States. The latch locks are manufactured only in Japan. NIST contacted U.S. representatives of eight manufacturers, and four responded with immediate availability of twistlocks. NIST purchased test specimens from the following manufacturers.

$\begin{array}{lll}\text { Manufacturer } & \text { Model Number } & \text { Figure } \\ \text { All Set Marine } & \text { C5AM } & 3.1 \\ \text { MacGregor-Conver } & \text { CV-20/2 (dual function) } & 3.2 \\ \text { Peck \& Hale } & \text { F738-M-1 } & 3.3 \\ \text { Taiyo Seiki } & \text { NA-3 } & 3.4 \\ \text { Taiyo Seiki } & \text { NA-7 (latch lock) } & 3.5\end{array}$

In addition to new twistlocks, NIST obtained two types of used twistlocks from a terminal operator.

$\begin{array}{llc}\text { Manufacturer } & \text { Model Number } & \text { Figure No. } \\ \text { All Set Marine } & \text { C5AM-DF (dual function) } & 3.6 \\ \text { MacGregor-Conver } & \text { CV-14 } & 3.7\end{array}$

The semi-automatic twistlocks are comprised of a single-piece steel shaft encased in a steel housing. The shaft has an upper and a lower cone that are oriented in different directions and fit inside the corner fittings. Some of the non-dual-function twistlocks have either a flat top upper cone (Figs. 3.1 and 3.7) or a pointed upper cone (Figs. 3.3 and 3.4). All dual-function twistlocks have pointed top and bottom cones (Figs. 3.2 and 3.6). Dual-function twistlocks facilitates the fitting and removal of twistlocks without affecting the container loading and unloading operations.

A latch lock has a locking flange on one side of the housing and a latch mechanism on the other side that works like a door latch (Fig. 3.5). When a latch lock is inserted into the corner fitting, the horizontal sliding latch is extended inside the corner fitting, thereby locking the latch lock to the corner fitting.

Peck \& Hale Model F463-1R and F463-2R corner fittings were used to make the test fixtures for tension testing of twistlocks and latch locks, see Fig. 4.2. 


\subsection{Specimen identification}

The following designations are used to identify test specimens.

\begin{tabular}{|c|c|c|}
\hline Manufacturer & Designation & $\underline{\text { Age }}$ \\
\hline All Set Marine/C5AM & ASM-T-N & New \\
\hline All Set Marine/C5AM-DF & ASM-T-U & Used \\
\hline MacGregor-Conver/CV-20/2 & CON-T-N & New \\
\hline MacGregor-Conver/CV-14 & CON-T-U & Used \\
\hline Peck \& Hale/F738-M-1 & P\&H-T-N & New \\
\hline Taiyo Seiki/NA-3 & TYS-T-N & $\mathrm{Ne}$ \\
\hline Taiyo Seiki/NA-7 & TYS-L-N & $\mathrm{Ne}$ \\
\hline
\end{tabular}

The letters "T" and "L" indicate that the connector is either a twistlock or a latch lock, respectively. 


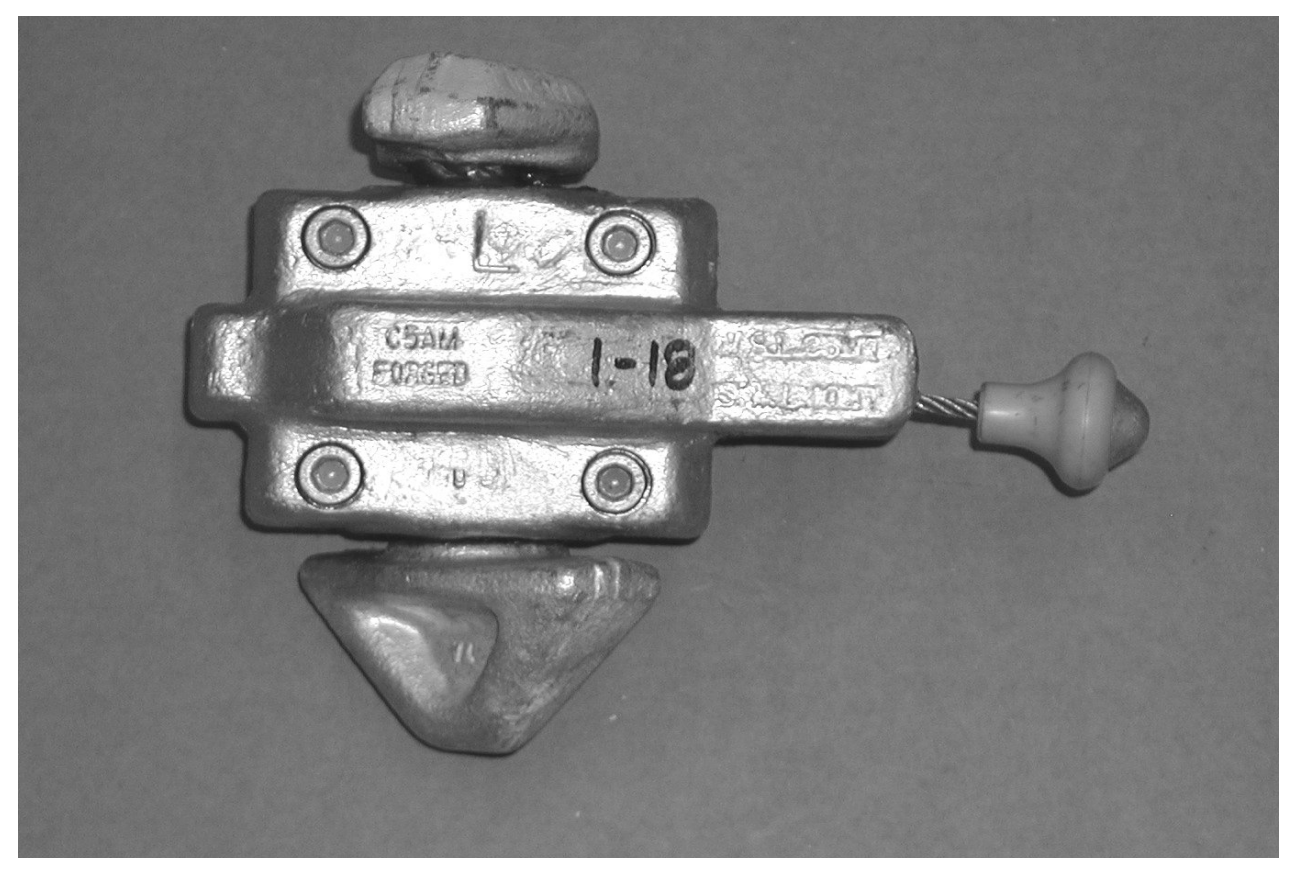

Figure $3.1 \quad$ All Set Marine C5AM (Twistlock)

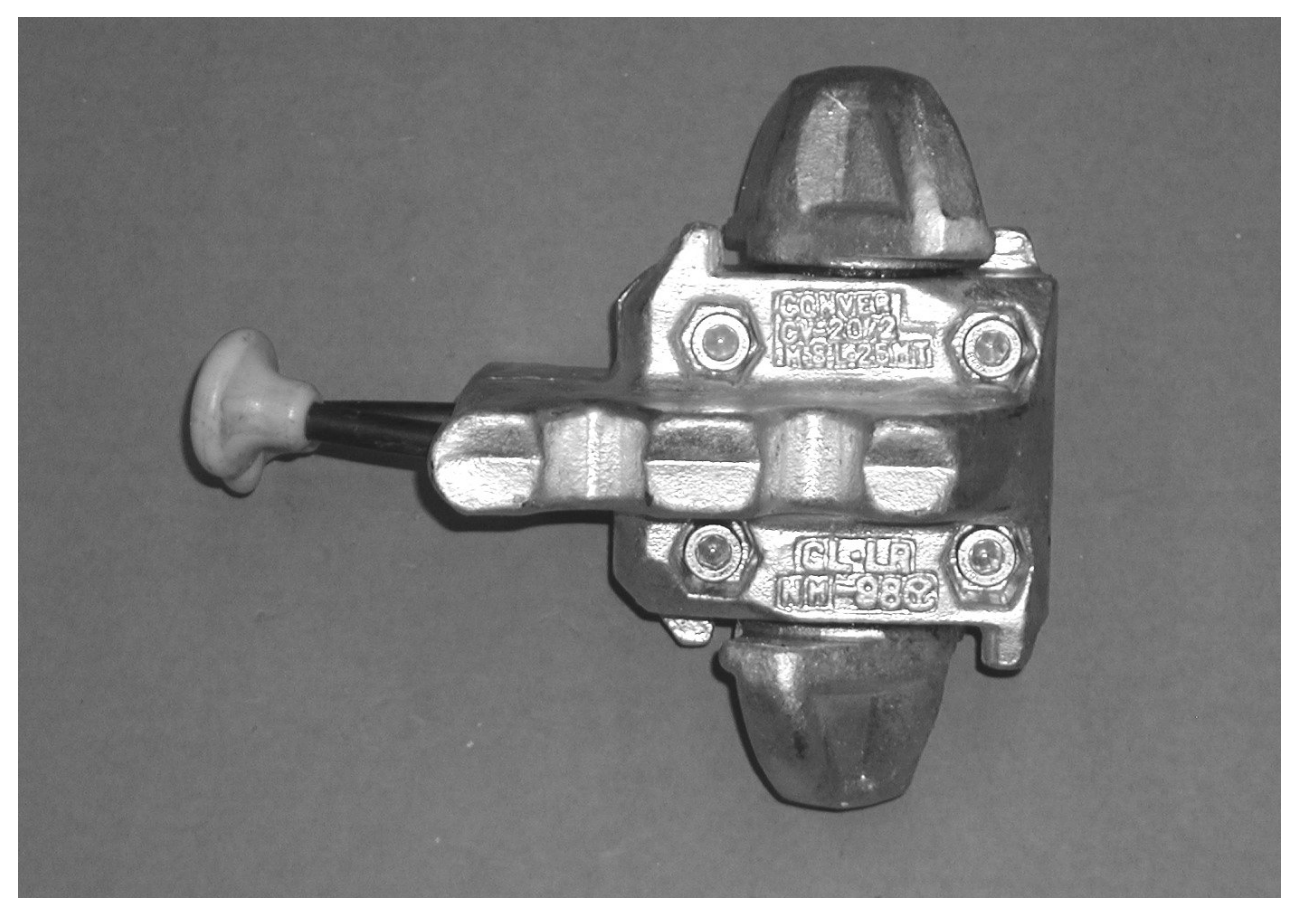

Figure 3.2 MacGregor-Conver CV-20/2 (Twistlock) 


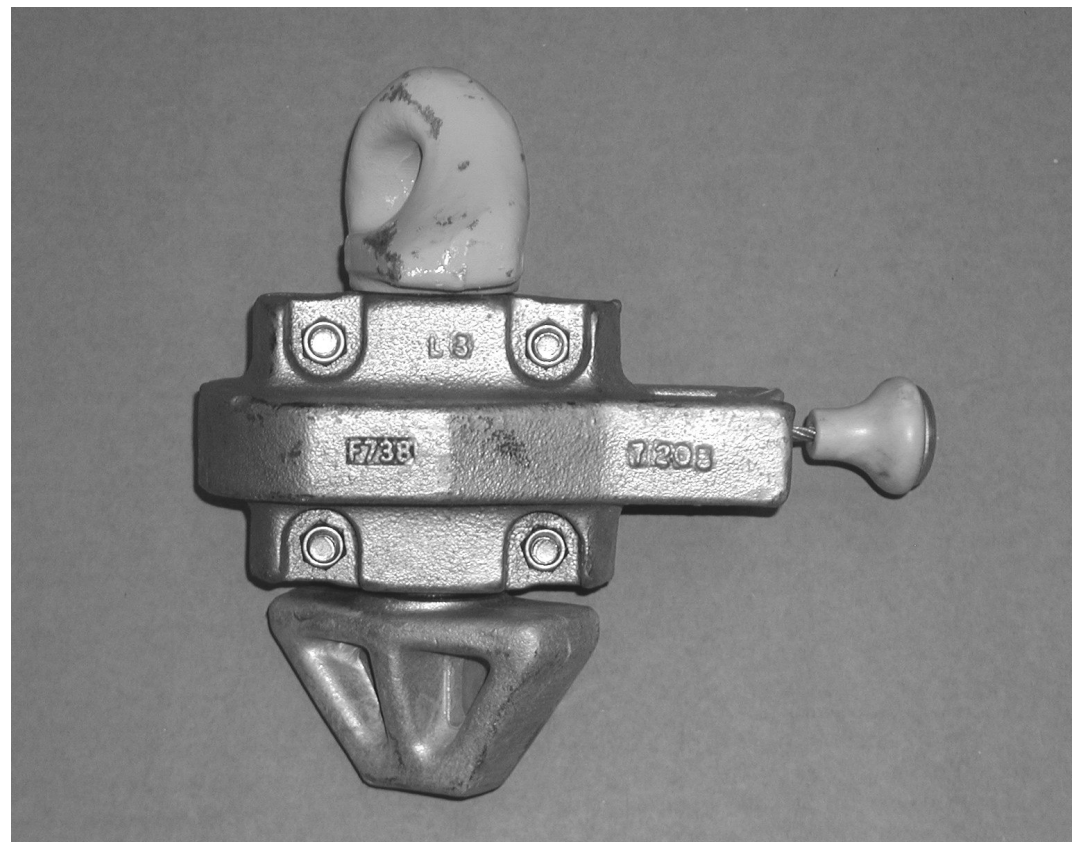

Figure 3.3 Peck \& Hale F738-M-1 (Twistlock)

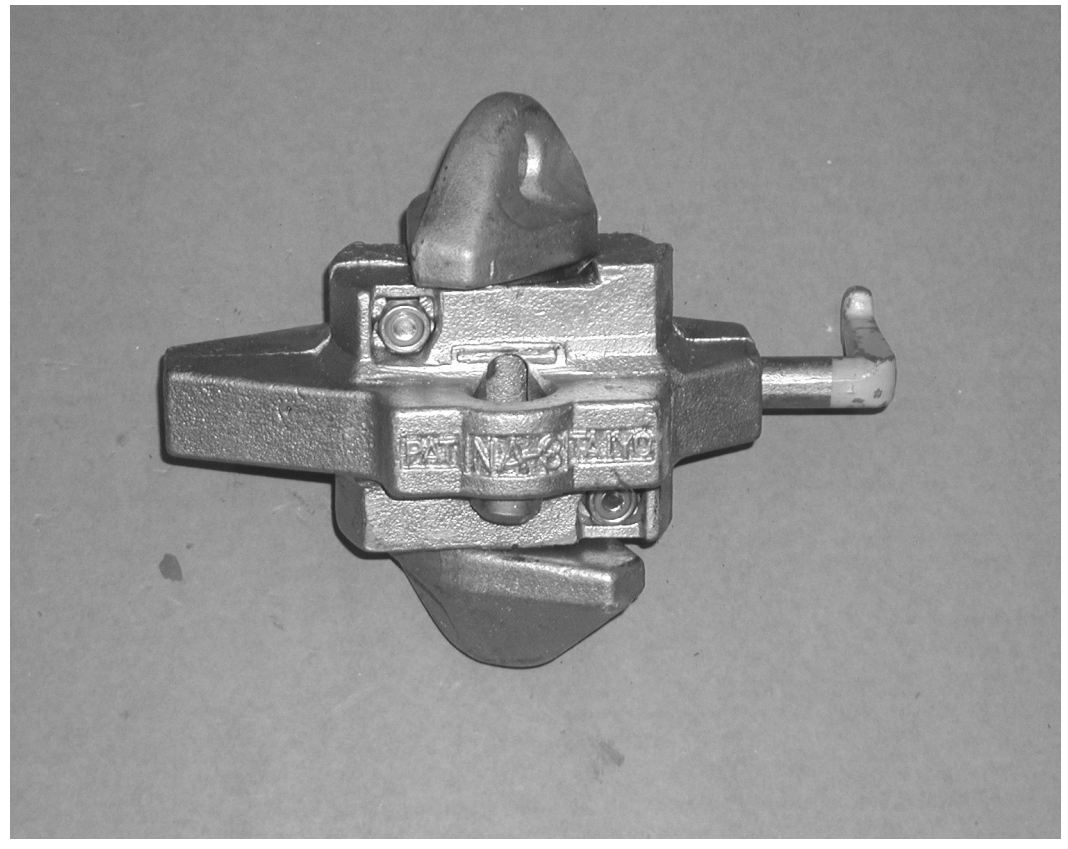

Figure 3.4 Taiyo Seiki NA-3 (Twistlock) 


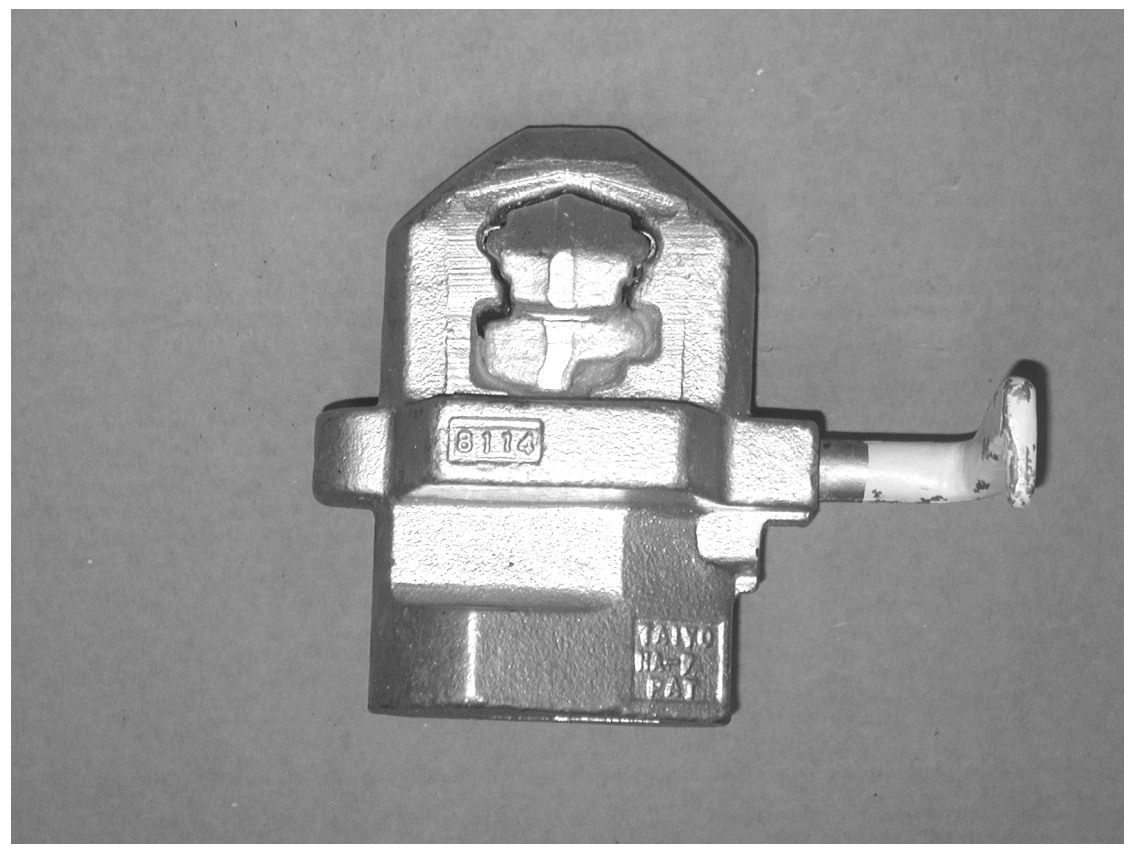

(a) Front View

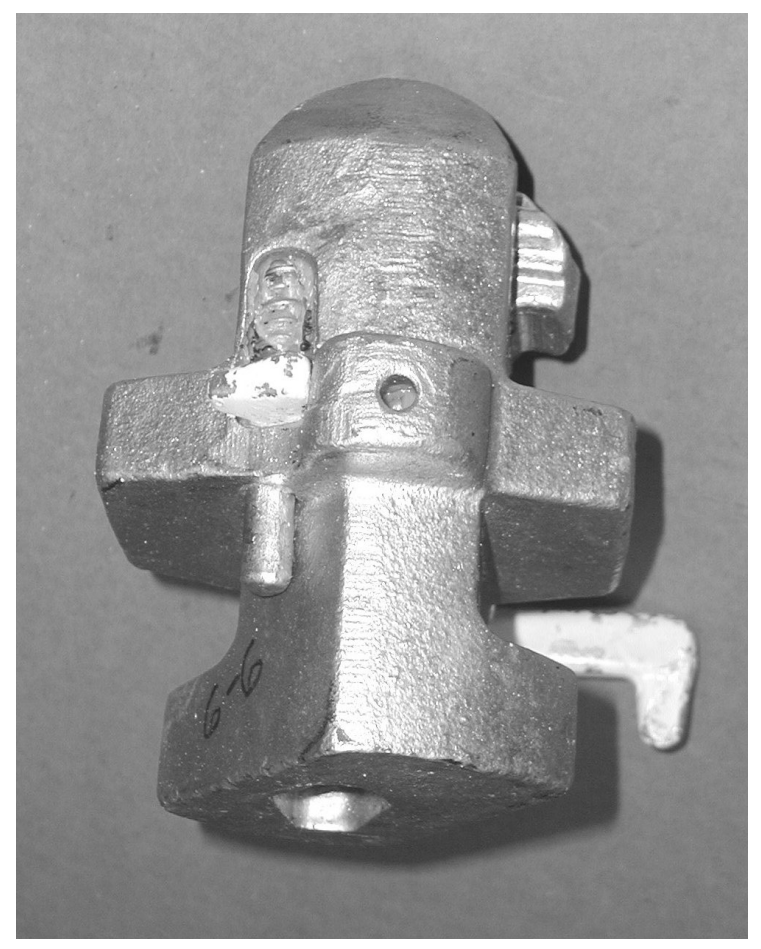

(b) Side View

Figure 3.5 Taiyo Seiki NA-7 (Latch Lock) 


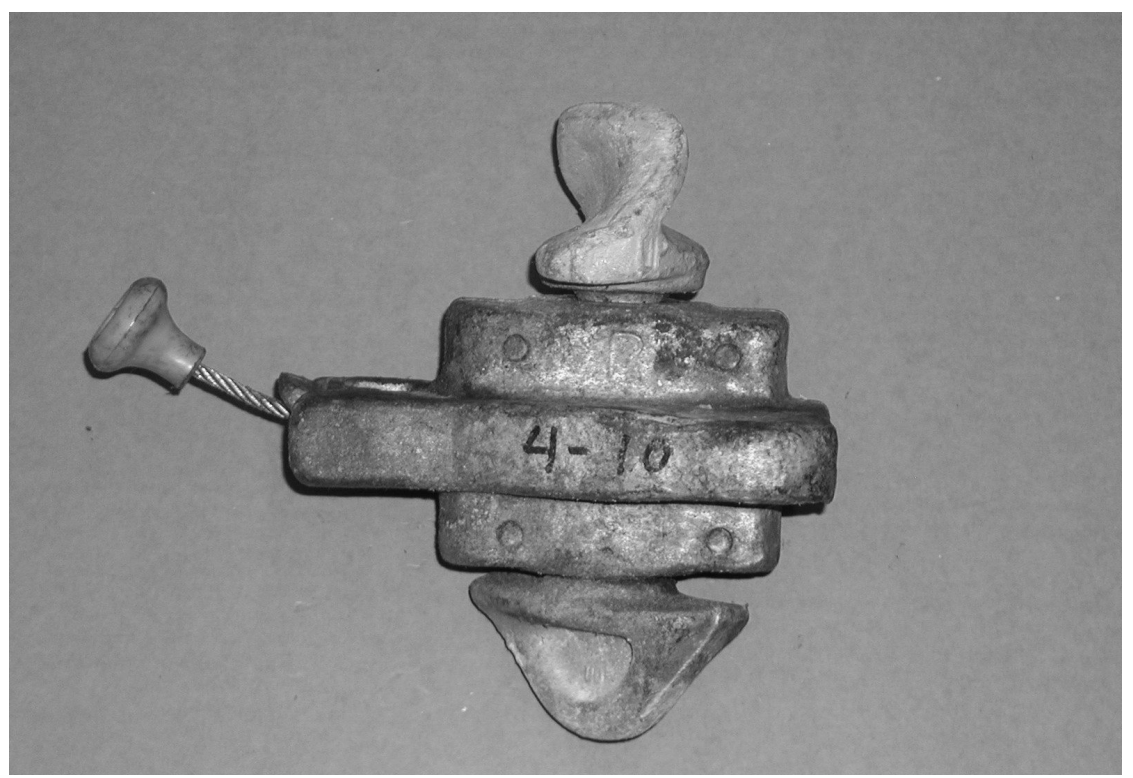

Figure 3.6 All Set Marine C5AM-DF

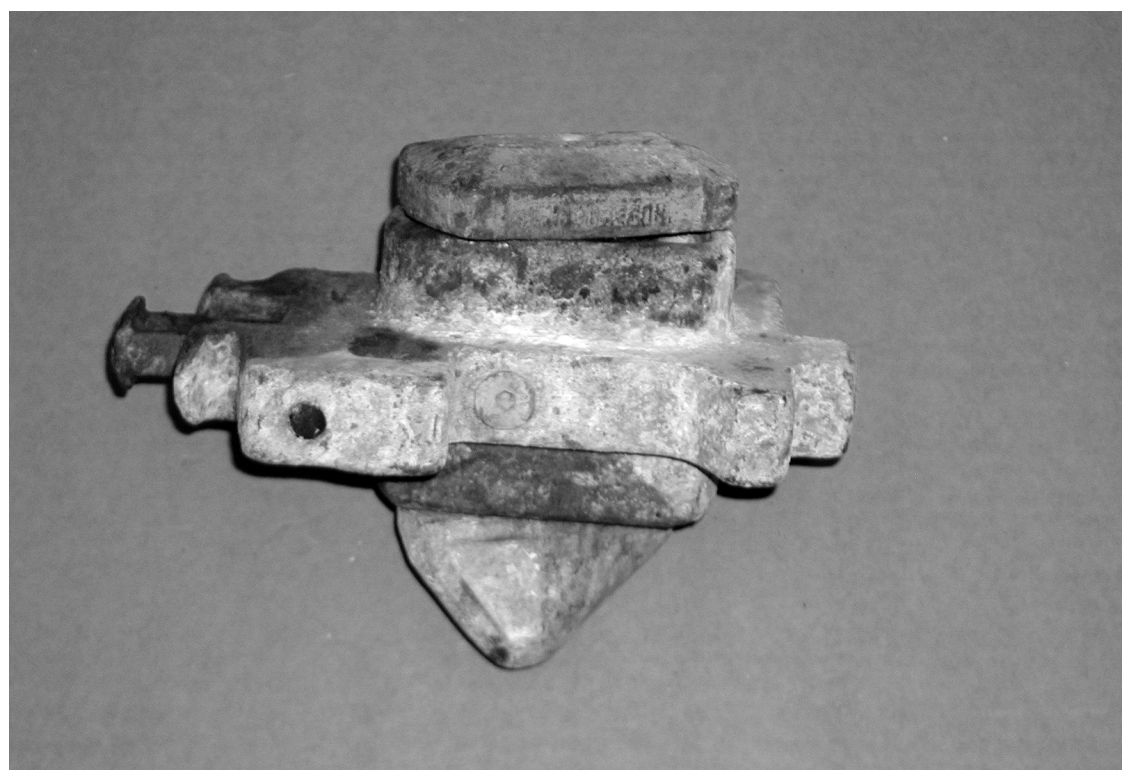

Figure 3.7 MacGregor-Conver CV-14 


\subsection{TEST METHODS}

\subsection{Tension capacity of twistlocks}

The purpose of this set of tests was to determine the tensile capacity of twistlock shafts. For this purpose, a special tension test fixture was fabricated as shown in Fig. 4.1. The fixture was placed into a $1775 \mathrm{kN}$ (400 $000 \mathrm{lbf}$ ) Tinius-Olsen universal testing machine. The accuracy of the testing machine in tension is $0.0034 \%$. The dimensions of the apertures in the top and bottom cylindrical fittings were the same as those specified in the ISO 1161 Standard [1] for corner fittings. Heat treating process (quenching and tempering) was used to harden the cylindrical fittings.

The capacity of a twistlock is limited by the capacity of the shaft to which the top and bottom cones are attached. To observe the mode and location of failure, the shaft was removed from the twistlock housing, and tested. Since the cones at the shaft ends are not oriented in the same direction and to avoid damage to the test fixture, the cylindrical fittings were rotated with respect to each other so that a maximum bearing area could be attained between the surface of the cone and the fitting. This was accomplished by rotating the fittings so that both the top and bottom cones were perpendicular $\left(90^{\circ}\right)$ to the long axis of the opening in the fitting. It should be noted that in actual use, the bottom cone, which locks automatically into the top corner fitting of a container, rotates less than $90^{\circ}$, which results in less than the maximum attainable bearing area.

The load was applied at a rate of $444 \mathrm{kN} / \mathrm{min}(100000 \mathrm{lbf} / \mathrm{min})$ until the specimen (shaft) fractured.

\subsection{Tension capacity of twistlock and latch lock assemblies}

The purpose of these tests was to determine the capacity and to identify the weakest link of the interbox connector-corner fitting assembly in tension. To simulate field conditions, twistlocks and latch locks were tested together with corner fittings. The test setup and fixture are shown in Fig. 4.2. High strength nuts were welded to $38 \mathrm{~mm}(1 \quad 1 / 2$ in) thick steel plates, which were in turn welded to the top and bottom corner fittings. This was done to ensure proper transfer of the load to the walls of the corner fitting without breaking its top plate. High strength bolts, which were screwed into the nuts, were fastened to the moving and fixed heads of the Tinius-Olsen testing machine. Because the corner fittings were severely deformed or damaged during each test, a new set of corner fittings was used for each test. This required fabrication of many sets of test fixtures.

For this series of assembly tests, the corner fittings were not rotated to attain a maximum bearing area between the cone and the inner surface of the corner fitting as was done for the twistlock tension capacity test. A twistlock or latch lock was placed between the top and bottom corner fittings similar to the field condition, see Fig. 4.2 (b). 
A loading rate of $444 \mathrm{kN} / \mathrm{min}$ (100 $000 \mathrm{lbf} / \mathrm{min})$ was maintained until failure occurred.

\subsection{Compression capacity of twistlock and latch lock assemblies}

This set of tests was conducted to determine the capacity of the interbox connector and corner fitting assembly in compression. Figure 4.3 shows the setup for the compression test. A twistlock or latch lock was inserted into a top corner fitting, and placed under the moving head of a stiff $4448 \mathrm{kN}$ (1000 $000 \mathrm{lbf}$ ) capacity Baldwin/Prism compression testing machine. The accuracy of the testing machine in compression is $0.0066 \%$. The load was applied at $444 \mathrm{kN} / \mathrm{min}(100000 \mathrm{lbf} / \mathrm{min})$ through a flat steel plate which was placed between the loading head and the top of the cone.

The test specimen was first loaded to $222 \mathrm{kN}$ (50 $000 \mathrm{lbf}$ ) without stopping, and unloaded for examination. Beyond this point, the load was increased in $44.5 \mathrm{kN}$ (10 $000 \mathrm{lbf})$ increments. At each load increment level, the specimen was unloaded to examine the functioning of the twistlock and any permanent deformation of the assembly. Testing was terminated when the twistlock failed to function or when permanent deformation or damage to the assembly was observed.

\subsection{Tensile strength of twistlock shaft materials}

These tests were performed to obtain the tensile stress-strain characteristics of the shaft materials of twistlocks. The test specimens were prepared from the shafts of twistlocks. The shaft was machined to a diameter of about $26 \mathrm{~mm}$ (1 in), and two strain gages $(5 \mathrm{~mm}$ gage length) were placed $180^{\circ}$ apart at the mid height of the specimen (Fig. 4.4). Prior to each test, the shaft diameter was measured at several places using a micrometer. The cross sectional area of the shaft, which was computed using the average of the measured diameters, was used to determine the tensile strength. The test setup was the same as that described in Section 4.1. Applied loads and strains were recorded using a data acquisition system and processed by a computer. The specimens were tested according to ASTM Test Methods A370-99a [3]. 


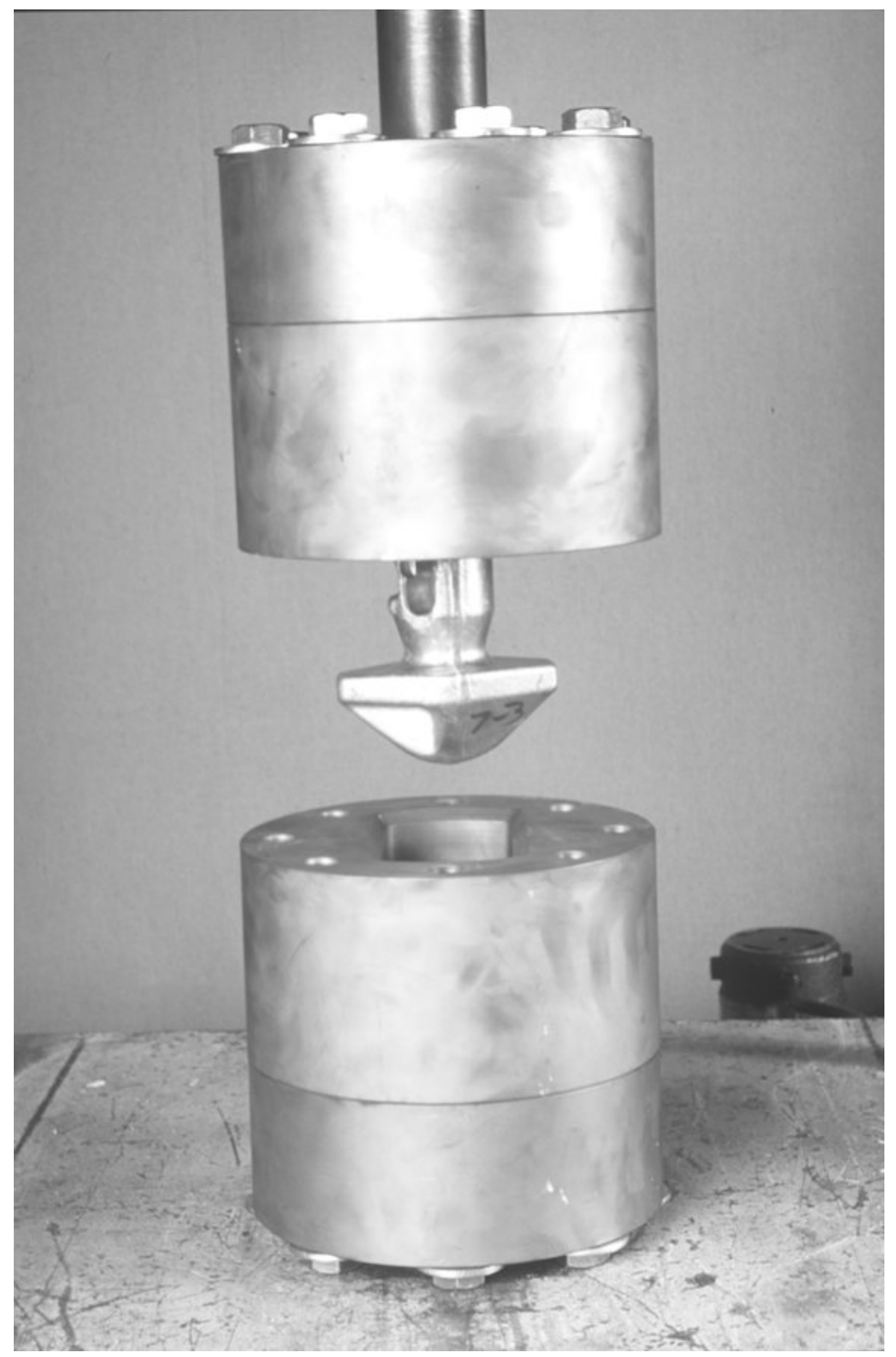

Figure 4.1 Tension Test Fixture for Twistlock Shafts 


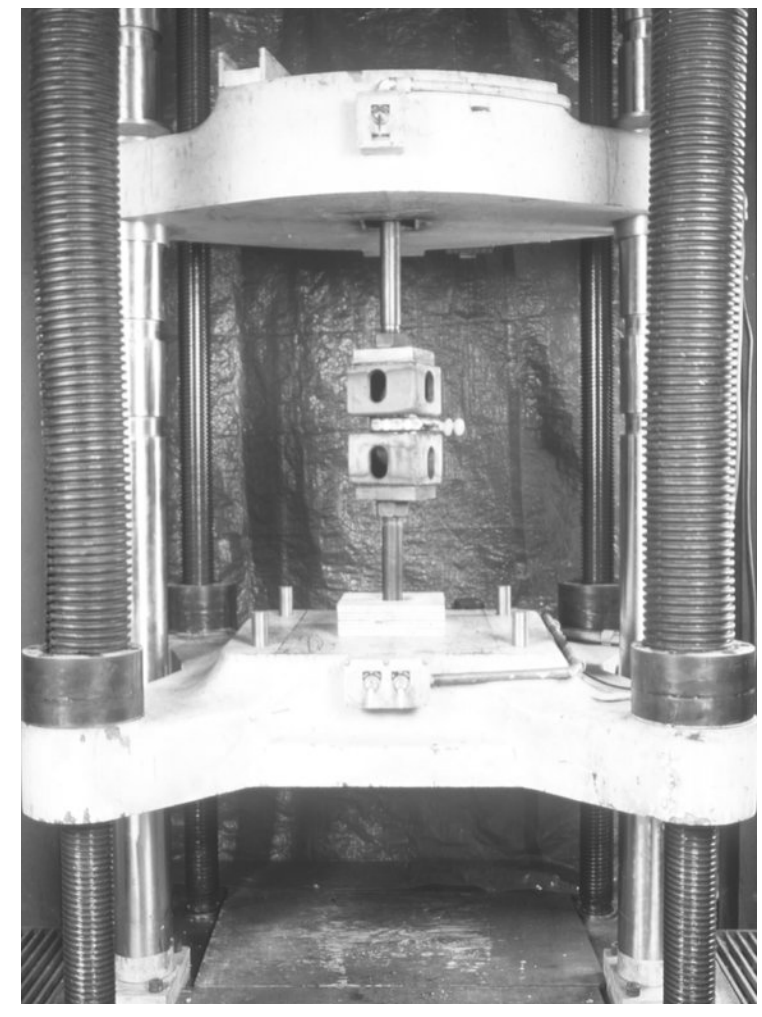

(a) Tension Test Setup

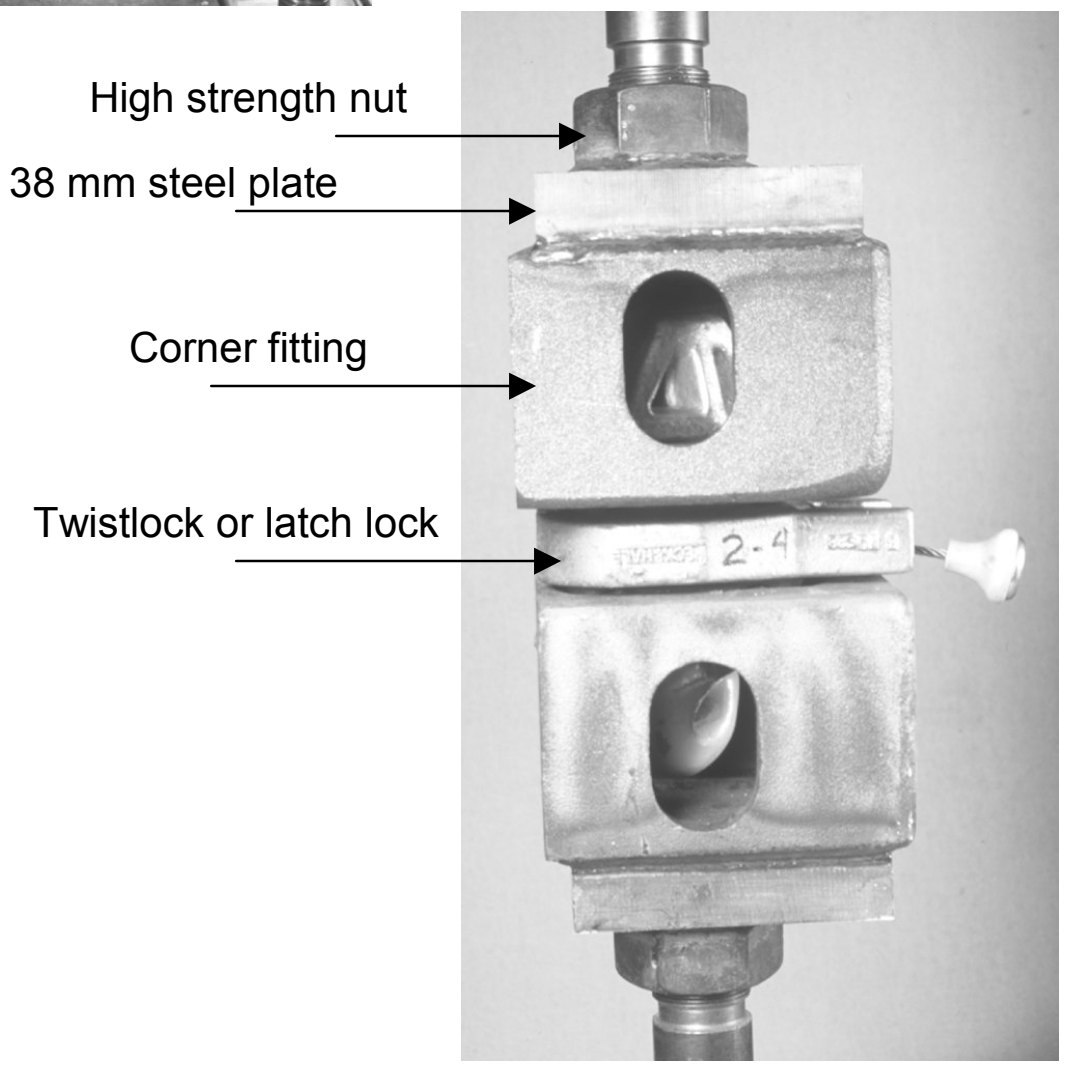

(b) Test Assembly

Figure 4.2 Tension Test Setup for Twistlock and Latch Lock Assembly 


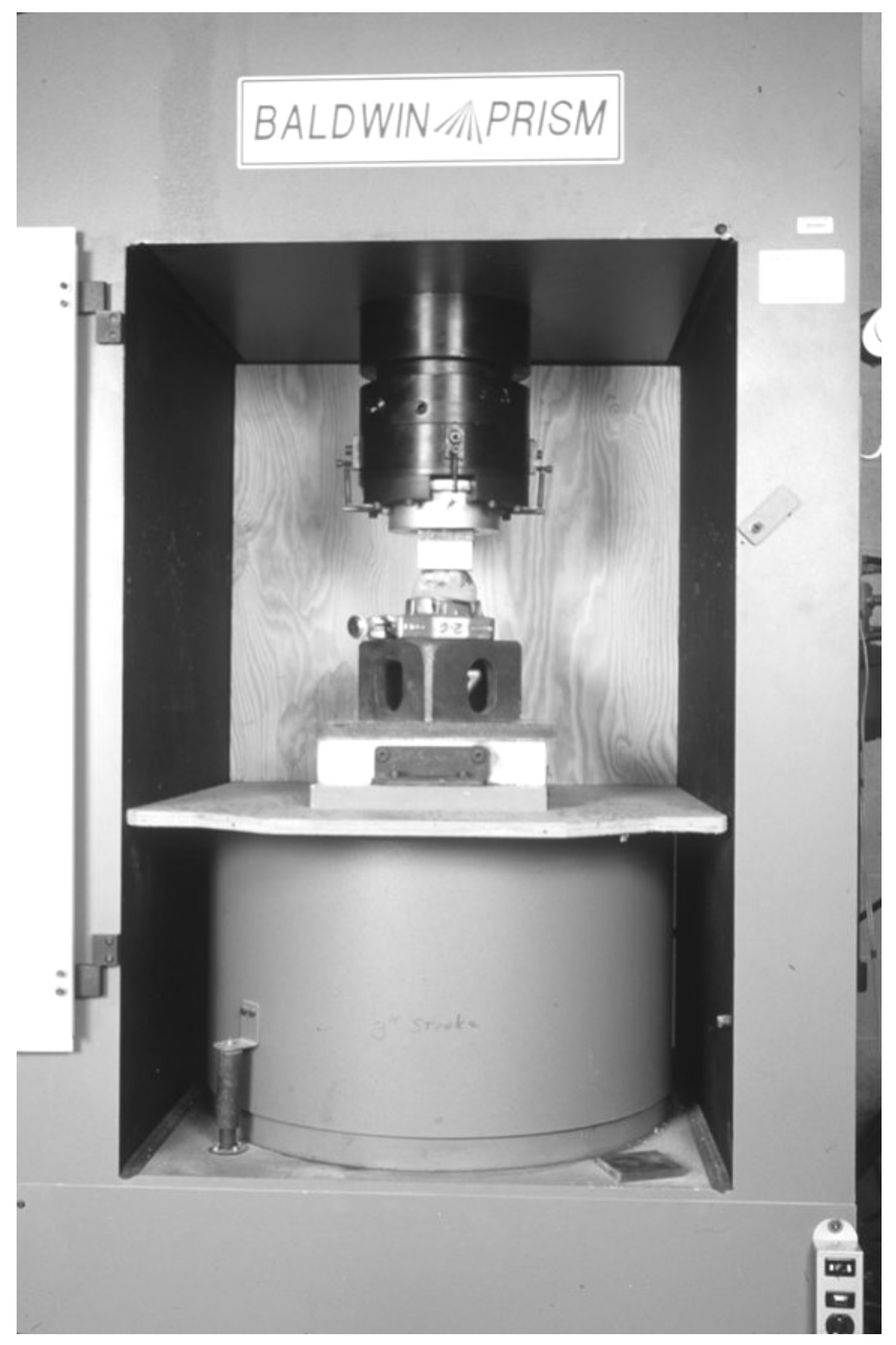

Figure 4.3 Compression Test Setup 


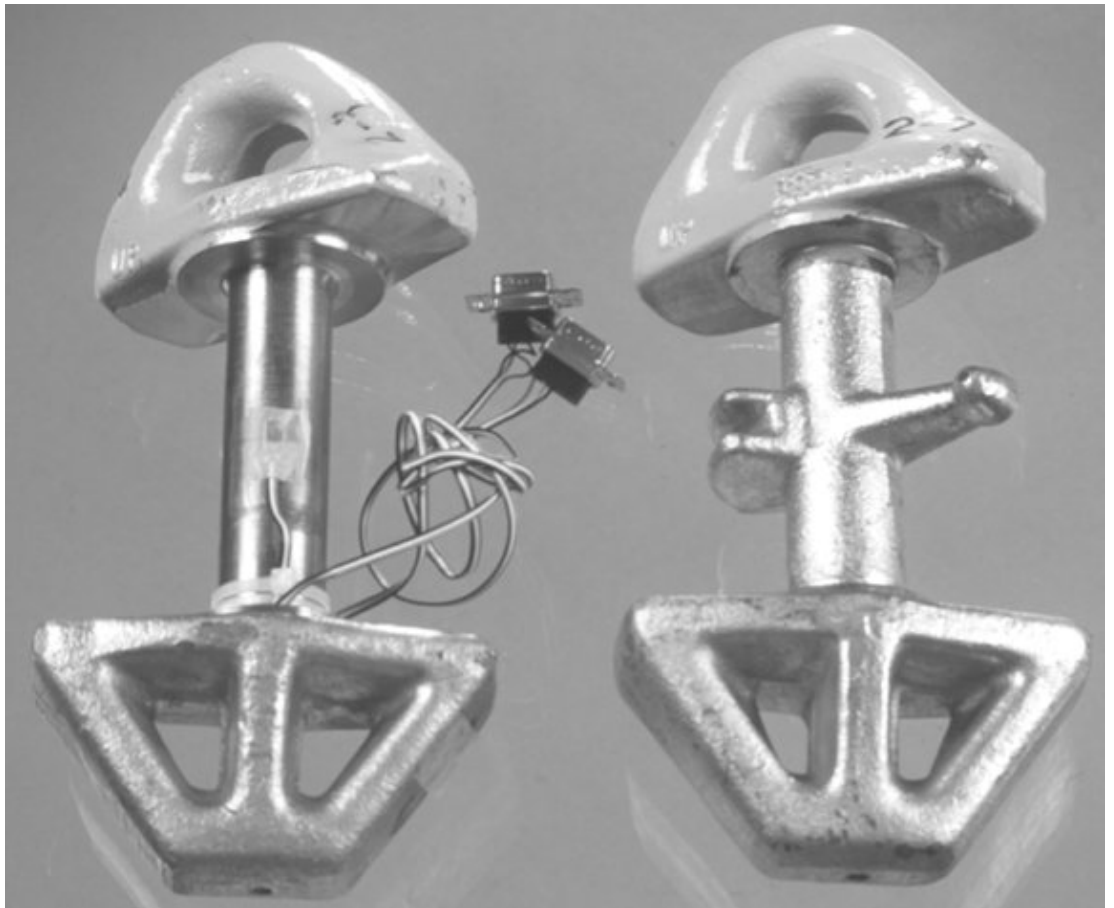

Figure 4.4 Tensile Strength Test Specimen 


\subsection{TEST RESULTS}

\subsection{Tension capacity of twistlock shafts}

Table 5.1 lists the failure loads of twistlock shafts loaded in tension using the special test fixture described in Section 4.1. As seen from the table, a replicate test was made for each group. Depending upon the composition of metal, the shafts fractured either in brittle or ductile modes. Examples of brittle, ductile, and ductile-shear modes of failure of the shafts are shown in Figs. 5.1, 5.2, and 5.3, respectively.

Latch locks were tested using a test fixture made with corner fittings, and the test results are reported in Section 5.2.

The ultimate tensile strengths ranged from $562 \mathrm{kN}$ (126 $400 \mathrm{lbf})$ to $802 \mathrm{kN}$ (180 $300 \mathrm{lbf}$ ). Similar test results were also reported by Anderson [4], wherein the ultimate loads ranged from $477 \mathrm{kN}(107000 \mathrm{lbf})$ to $797.1 \mathrm{kN}(179200 \mathrm{lbf})$. The ISO 1161 Standard [1] requires that the top corner fitting be designed for a lifting load of $150 \mathrm{kN}$ (33 $700 \mathrm{lbf}$ ). While this requirement is not directly related to vertical tandem lifts (VTL), the magnitudes of the ultimate loads of the twistlock shafts, regardless of their modes of failure, are substantially greater than the ISO minimum design load of the top corner fitting.

Although a limited number of used connectors were tested, the values in Table 5.1 do not indicate that used twistlocks are weaker than new twistlocks.

\subsection{Tension capacity of twistlock and latch lock assemblies}

Table 5.2 lists the maximum tensile loads of twistlock and latch lock assemblies, and brief descriptions of their failure modes. As described in Section 4.2, in this series of tests, each specimen was loaded with top and bottom corner fittings.

Comparing the ultimate loads in Tables 5.1 and 5.2, it can be seen that the capacity of the assembly is limited by failure of the corner fitting. Failure was brought about by large permanent deformations of the aperture of the corner fitting and/or shearing at the perimeter of the aperture (Figs. 5.4 and 5.5). A relatively small bearing area of the cone on the corner fitting caused a concentration of force near the edge of the aperture, and as a result, the edge of the cone sheared through the top plate of the corner fitting.

Figure 5.6 shows the fracture of the shaft after the cone has partially dislodged from the corner fitting. A large deformation of one side of the aperture of the corner fitting created a high bending moment in addition to the axial load on the shaft. This caused the shaft to fracture, and at the same time the cone to shear the corner fitting. 
The latch locks were tested with varying degrees of extension of the latch. At $100 \%$ extension, the latch of TYS-L-N latch locks extends $10.7 \mathrm{~mm}(0.42 \mathrm{in})$ from the housing. Two additional tests were made with the latch extended $76 \%$ and $57 \%$.

Because there is only one latch, a latch lock applies an eccentric load on the corner fitting. This results in prying action in addition to tension load on the corner fitting. The degree of deformation and shearing of a part of the corner fitting depends on the amount of contact between the latch and the inner surface of the corner fitting. Figure 5.7 shows how the latch sheared through the edge of the aperture of a corner fitting.

The maximum test loads ranged from $408 \mathrm{kN}(69500 \mathrm{lbf})$ to $710 \mathrm{kN}$ (159 $000 \mathrm{lbf})$ for the twistlock-corner fitting assemblies, whereas the maximum test load for a latch lockcorner fitting assembly with $100 \%$ latch extension was $309 \mathrm{kN}$ (69 $500 \mathrm{lbf}$ ). When the latch was extended to only $76 \%$ and $57 \%$ of full extension, the maximum loads dropped substantially to $203 \mathrm{kN}$ (45 $700 \mathrm{lbf})$ and $90 \mathrm{kN}(20300 \mathrm{lbf})$, respectively. Thus, the maximum test loads of the latch lock-corner fitting assemblies are considerably less than those of the twistlock-corner fitting assemblies.

The ISO Standard 1496-1 [2] requires that the entire container structure be able to support twice the maximum gross weight of the container without consideration of any dynamic or impact effects (at rest state). If dynamic effects are considered together with this implied factor of safety of 2 , the corner fitting must have an ultimate capacity of at least $300 \mathrm{kN}$ (67 $400 \mathrm{lbf})$. This requirement applies to lifting the full weight of a container with cargo. The test loads indicate that twistlock-corner fitting assemblies would most likely meet this requirement. On the other hand, even with the latch fully extended, latch lock-corner fitting assemblies would less likely meet this requirement.

\subsection{Compression capacity of twistlock and latch lock assemblies}

Twistlocks and latch locks must remain functional after being subjected to compression force. As described in Section 4.3, the test specimens were unloaded beginning at $222 \mathrm{kN}(50000 \mathrm{lbf})$ to examine whether the connector functioned properly and to check for visible damage. Subsequently, the specimens were examined at each $56 \mathrm{kN}$ (10 $000 \mathrm{lbf})$ increment. The maximum capacity was determined as one load increment level below the load at which disfunctioning of the twistlock or latch lock was first noted. The maximum loads so determined for six tests are listed in Table 5.3. Figures 5.8 through 5.13 show damage to the twistlocks and latch locks assemblies. Comparing the tensile and compressive load capacities in Tables 5.2 and 5.3, it is observed that the capacities of the assemblies in compression are considerably higher than their capacities in tension. 


\subsection{Tensile strength of twistlock shafts}

The tensile stress-strain relationships of the shaft materials of ASM-T-N, CON-T-N, and P\&H-T-N (two specimens each) are shown in Figs. 5.14 through 5.20. The stress is computed by dividing the applied load by the cross sectional area of the shaft. The strains were measured using strain gages. Strain values in the non-linear range beyond 0.02 may not be true strains because strain values have exceeded the capacity of the gages. Estimated yield strengths from the stress-strain curves range from $660 \mathrm{MPa}$ $(95 \mathrm{ksi})$ to $950 \mathrm{MPa}(135 \mathrm{ksi})$. The ultimate tensile strength of the six tests ranged from $792 \mathrm{MPa}(116 \mathrm{ksi})$ to $1065 \mathrm{MPa}$ (155 ksi), and are listed in Table 5.4. These results indicate that the materials used for the tested twistlocks can be classified as high-strength steel. The test specimens of each group after fracture are shown in Figures 5.21, 5.22 and 5.23 .

\subsection{Measurement of load bearing areas}

The ISO Standard 1161 [1] requires a minimum bearing area on the horizontal part of the inner top surface of the top corner fitting of $800 \mathrm{~mm}^{2}\left(1.24 \mathrm{in}^{2}\right)$. Recently, an amendment to the ISO Standard 3874 [5] was proposed and approved (January 1999) at the committee level relative to the bearing area requirements. This amendment requires that the bearing area be at least $600 \mathrm{~mm}^{2}\left(0.93 \mathrm{in}^{2}\right)$ for connectors bearing on only one side of the corner fitting such as latch locks. Using a special test apparatus, the footprints of bearing of the top and bottom cones were measured. Since the ISO Standard 1161 [1] allows a tolerance of $+1.5 \mathrm{~mm}(+1 / 16 \mathrm{in})$ on the $63.5 \mathrm{~mm}(21 / 2 \mathrm{in})$ width of the cornerfitting aperture, the bearing areas were measured for $63.5 \mathrm{~mm}$ and $65 \mathrm{~mm}$ wide openings. The measured bearing areas are listed in Table 5.5. It is seen in the table that except for the latch lock, all twistlocks in the $63.5 \mathrm{~mm}(21 / 2$ in) opening have a sufficient bearing area to meet the ISO 1161 requirement. In the $65 \mathrm{~mm}$ opening, three twistlocks failed barely to meet the requirement. On the other hand, even with the latch fully extended, the bearing area of the latch lock is less than $50 \%$ of the current requirement of the ISO Standard 1161, as well as the amended requirement of the ISO Standard 3874. The bearing area would be substantially smaller when the latch is not fully extended. 
Table 5.1 Tension Capacity of Twistlock Shafts

\begin{tabular}{|l|c|c|l|}
\hline \multirow{2}{*}{ Specimen } & \multicolumn{2}{|c|}{ Maximum Test Load } & \multirow{2}{*}{ Mode of Failure } \\
\cline { 2 - 3 } & Kilonewton $(\mathrm{kN})$ & Pound-force $(\mathrm{lbf})$ & \\
\hline ASM-T-N & 562 & 126400 & Brittle \\
\hline ASM-T-N & 563 & 126500 & Brittle \\
\hline CON-T-N & 602 & 135500 & Ductile shear * \\
\hline CON-T-N & 591 & 132900 & Ductile shear \\
\hline P\&H-T-N & 651 & 146400 & Ductile * \\
\hline P\&H-T-N & 574 & 129000 & Ductile \\
\hline TYS-T-N & 687 & 154400 & Ductile shear \\
\hline TYS-T-N & 713 & 160200 & Ductile shear \\
\hline ASM-T-U & 778 & 175000 & Ductile \\
\hline ASM-T-U & 802 & 180300 & Ductile \\
\hline CON-T-U & 746 & 167800 & Brittle \\
\hline CON-T-U & 712 & 160000 & Brittle \\
\hline
\end{tabular}

* Brittle, ductile, and ductile shear ruptures occurred in the shaft. 
Table 5.2 Tension Capacity of Twistlock and Latch Lock Assemblies

\begin{tabular}{|l|c|c|l|}
\hline \multirow{2}{*}{ Specimen } & \multicolumn{2}{|c|}{ Maximum Test Load } & \multicolumn{2}{|c|}{ Failure Mode } \\
\cline { 2 - 4 } & Kilonewton (kN) & Pound-force (lbf) & $\begin{array}{l}\text { Pointed cone cut through } \\
\text { corner fitting }\end{array}$ \\
\hline ASM-T-N & 436 & 98200 & $\begin{array}{l}\text { Top cone pried off from } \\
\text { shaft in tension and bending }\end{array}$ \\
\hline P\&H-T-N & 408 & 106500 & $\begin{array}{l}\text { Pointed cone cut through } \\
\text { corner fitting }\end{array}$ \\
\hline TYS-T-N & 636 & 143000 & $\begin{array}{l}\text { Corner fitting deformed, top } \\
\text { cone dislodged }\end{array}$ \\
\hline ASM-T-U & 579 & 130200 & $\begin{array}{l}\text { Corner fitting deformed, and } \\
\text { pointed cone cut through } \\
\text { corner fitting }\end{array}$ \\
\hline CON-T-U & 710 & 159000 & $\begin{array}{l}\text { Shaft ruptured after pointed } \\
\text { cone cut partially through } \\
\text { corner fitting }\end{array}$ \\
\hline $\begin{array}{l}\text { TYS-L-N } \\
(100 \% \text { extension })\end{array}$ & 309 & $\begin{array}{l}\text { Latch cut through corner } \\
\text { fitting }\end{array}$ \\
\hline $\begin{array}{l}\text { TYS-L-N } \\
(76 \% \text { extension) }\end{array}$ & 903 & $\begin{array}{l}\text { Latch cut through corner } \\
\text { fitting }\end{array}$ \\
\hline $\begin{array}{l}\text { TYS-L-N } \\
(57 \% \text { extension) }\end{array}$ & 45700 & $\begin{array}{l}\text { Latch cut through corner } \\
\text { fitting }\end{array}$ \\
\hline
\end{tabular}

Table 5.3 Compression Capacity of Twistlocks and Latch Locks

\begin{tabular}{|l|c|c|c|}
\hline \multirow{2}{*}{ Specimen } & \multicolumn{2}{|c|}{ Maximum Test Load } & \multirow{2}{*}{ Figure No. } \\
\cline { 2 - 3 } & Kilonewton (kN) & Pound-force (lbf) & \\
\hline ASM-T-N & 667 & 150000 & 5.8 \\
\hline CON-T-N & 534 & 120000 & 5.9 \\
\hline P\&H-T-N & 756 & 170000 & 5.10 \\
\hline P\&H-T-N & 667 & 150000 & 5.11 \\
\hline TYS-T-N & 667 & 150000 & 5.12 \\
\hline TYS-L-N & 445 & 100000 & 5.13 \\
\hline
\end{tabular}


Table 5.4 Tensile Strength of Twistlock Shafts

\begin{tabular}{|l|l|l|l|l|}
\hline \multirow{2}{*}{ Specimen } & \multicolumn{3}{|c|}{ Tensile Strength in MPa (ksi) } & \multirow{2}{*}{ Mode of Failure } \\
\cline { 2 - 4 } & Test 1 & Test 2 & Average & \\
\hline ASM-T-N & $896(130)$ & $881(128)$ & $889(129)$ & Brittle \\
\hline P\&H-T-N & $792(116)$ & $818(119)$ & $805(118)$ & Ductile \\
\hline CON-T-N & $1000(145)$ & $1065(155)$ & $1033(150)$ & Ductile shear \\
\hline
\end{tabular}

Table 5.5 Bearing Areas on Corner Fitting

\begin{tabular}{|l|l|ll|ll|}
\hline Specimen & \multirow{2}{*}{$\begin{array}{c}\text { Cone } \\
\text { Position }\end{array}$} & \multicolumn{4}{|c|}{ Bearing Area in $\mathrm{mm}^{2}\left(\mathrm{in}^{2}\right)$} \\
\cline { 3 - 6 } & & \multicolumn{2}{|c|}{$63.5 \mathrm{~mm}$ Slot } & \multicolumn{2}{|c|}{$65 \mathrm{~mm}$ Slot } \\
\hline ASM-T-N & Top & 800 & $(1.24)$ & 787 & $(1.22)$ \\
& Bottom & 1741 & $(2.70)$ & 1703 & $(2.64)$ \\
\hline CON-T-N & Top & 903 & $(1.40)$ & 812 & $(1.26)$ \\
& Bottom & 916 & $(1.42)$ & 851 & $(1.32)$ \\
\hline P\&H-T-N & Top & 1690 & $(2.62)$ & 1658 & $(2.57)$ \\
& Bottom & 838 & $(1.30)$ & 774 & $(1.20)$ \\
\hline TYS-T-N & Top & 1070 & $(1.66)$ & 1032 & $(1.60)$ \\
& Bottom & 941 & $(1.46)$ & 870 & $(1.35)$ \\
\hline ASM-T-U & Top & 1716 & $(2.66)$ & 1645 & $(2.55)$ \\
& Bottom & 800 & $(1.24)$ & 716 & $(1.11)$ \\
\hline CON-T-U & Top & 987 & $(1.53)$ & 896 & $(1.39)$ \\
& Bottom & 935 & $(1.45)$ & 845 & $(1.31)$ \\
\hline TYS-L-N & Latch & 380 & $(0.59)$ & 329 & $(0.51)$ \\
& Bottom & 1109 & $(1.72)$ & 980 & $(1.52)$ \\
\hline
\end{tabular}




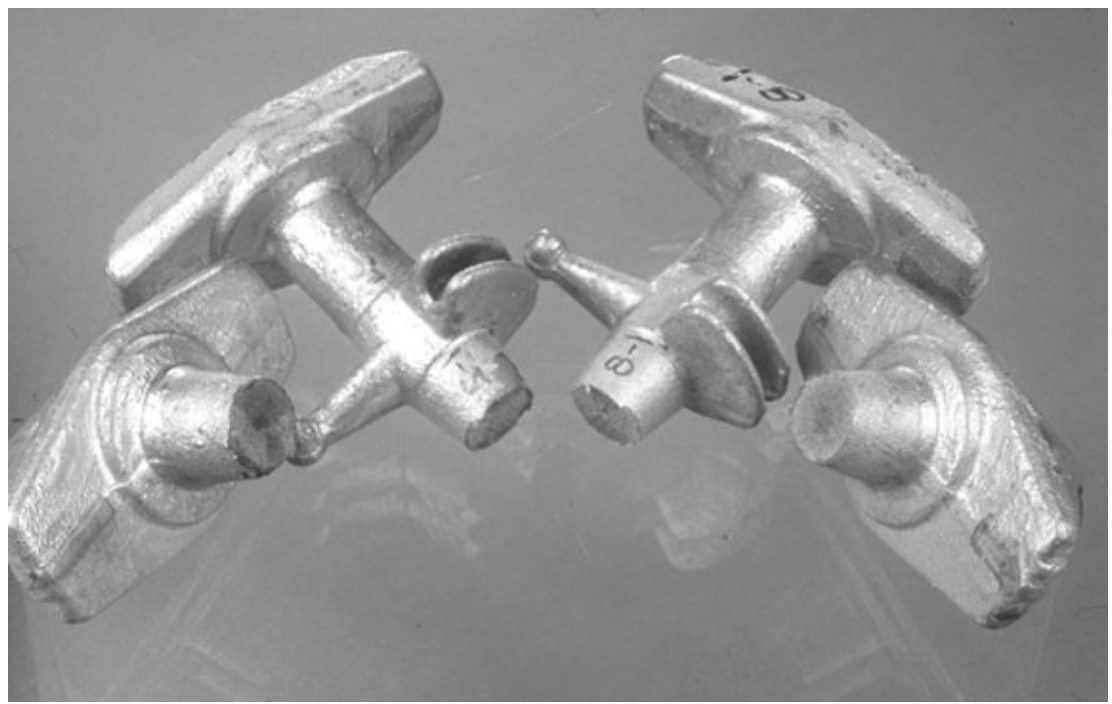

Figure 5.1 Brittle Mode of Failure of Shaft (ASM-T-N)

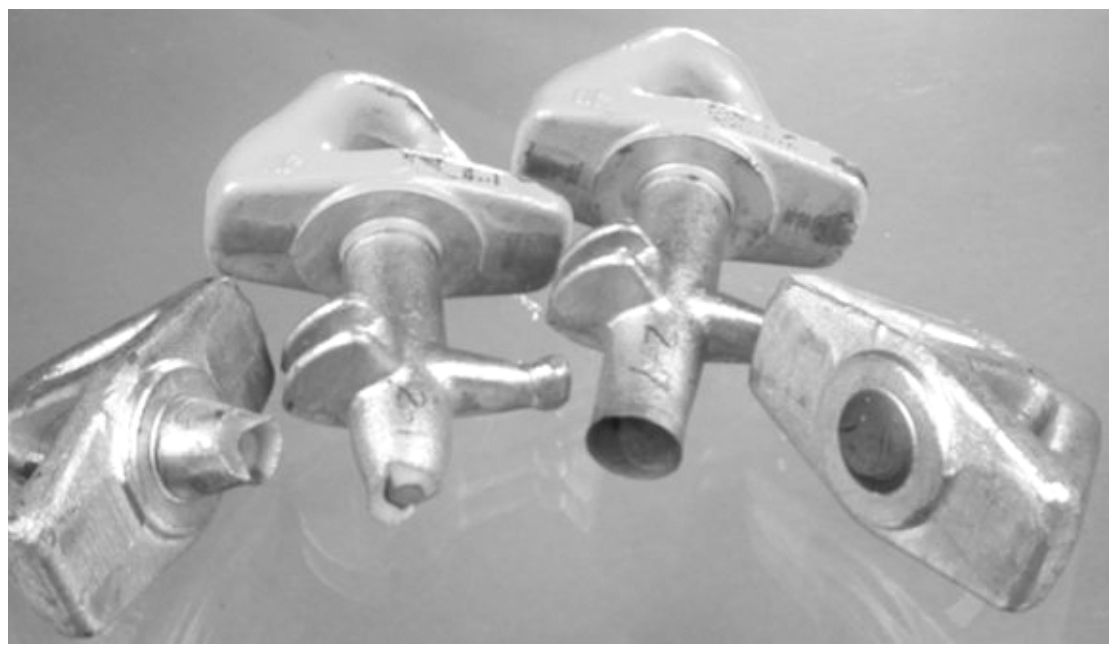

Figure 5.2 Ductile Mode of Failure of Shafts (CON-T-N) 


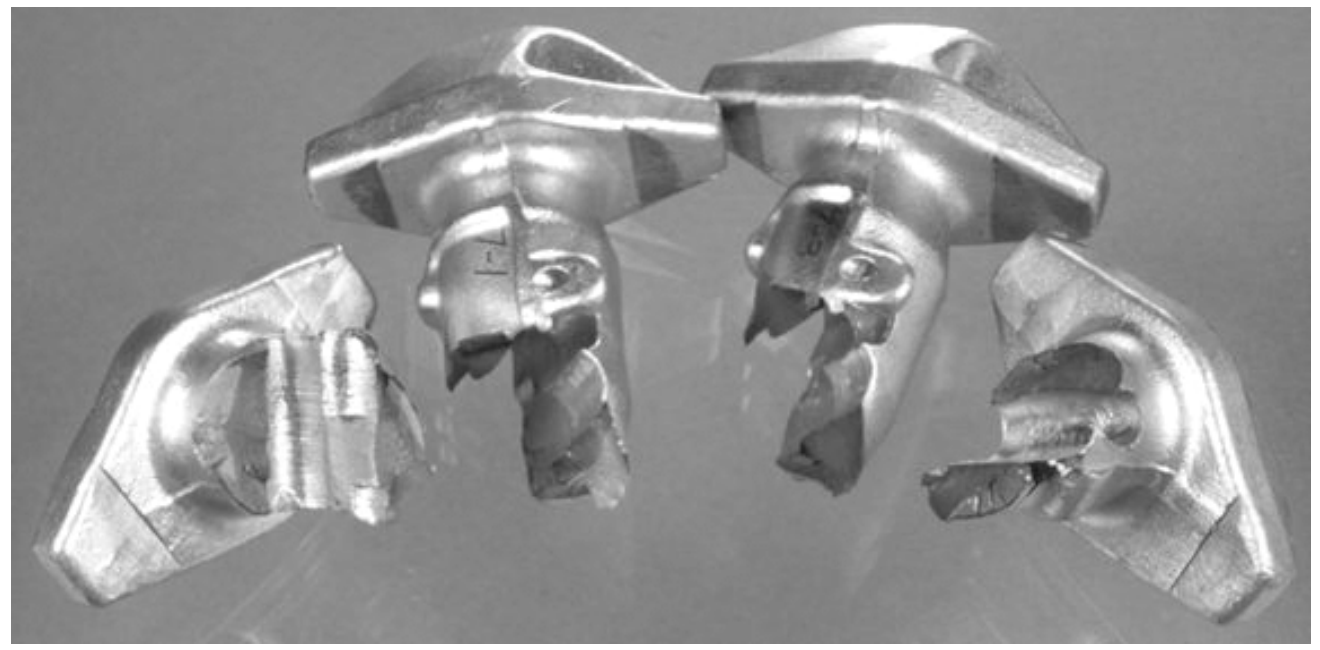

Figure 5.3 Ductile-Shear Mode of Failure of Shafts (TYS-T-N)

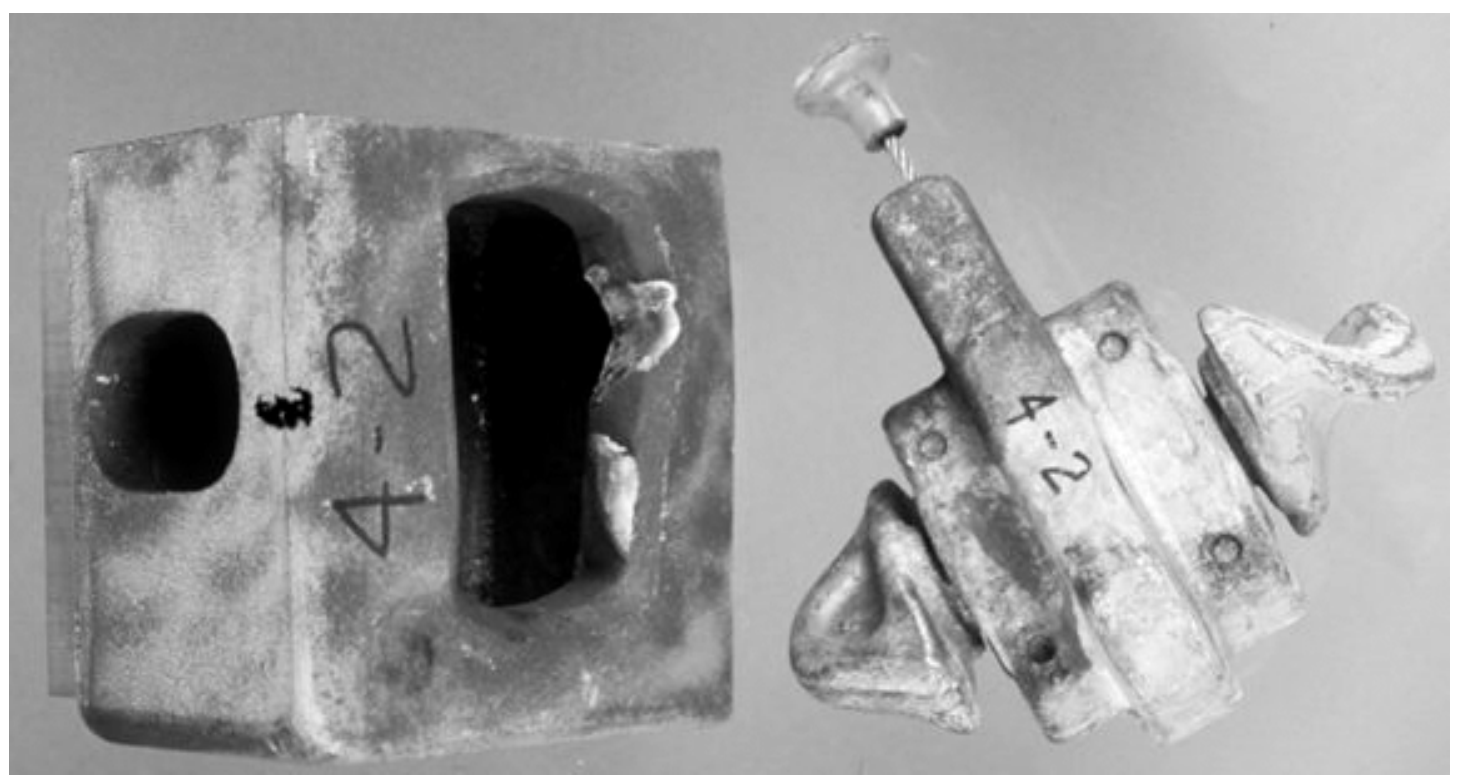

Figure 5.4 Damaged Corner Fitting in Tension Test of Assembly with Twistlock 


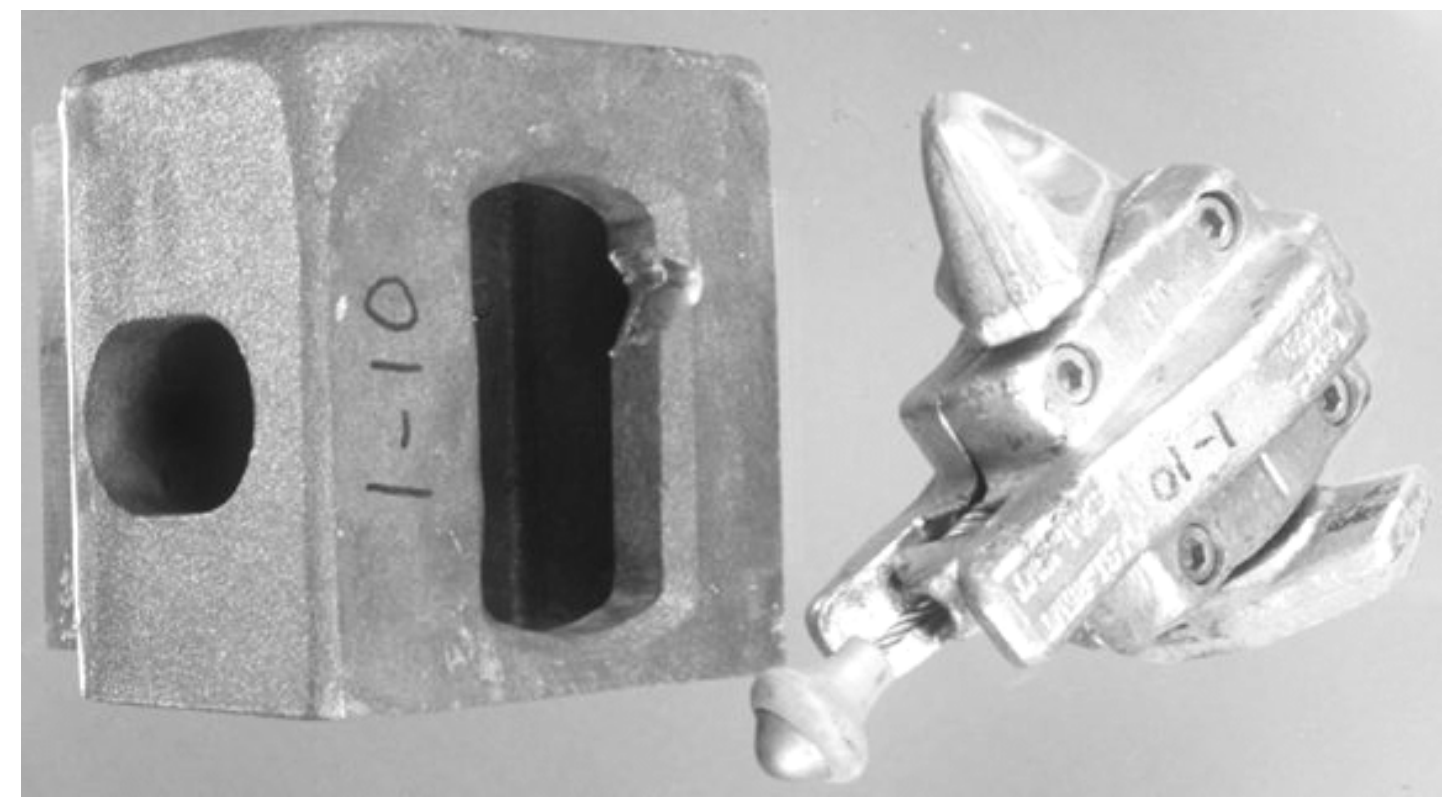

Figure 5.5 Shearing Failure of Corner Fitting

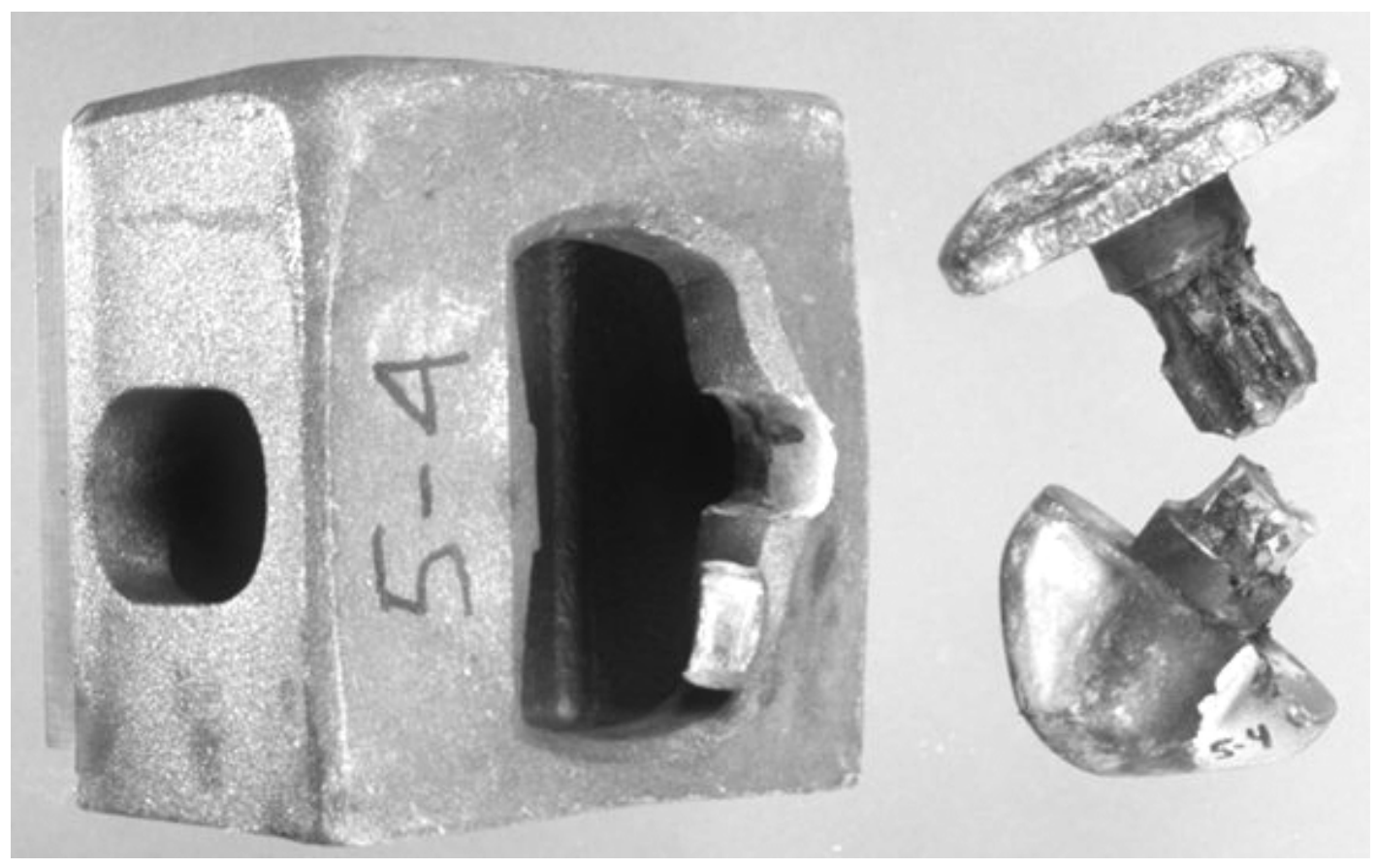

Figure 5.6 Fractured Shaft and Shearing Failure of Corner Fitting 


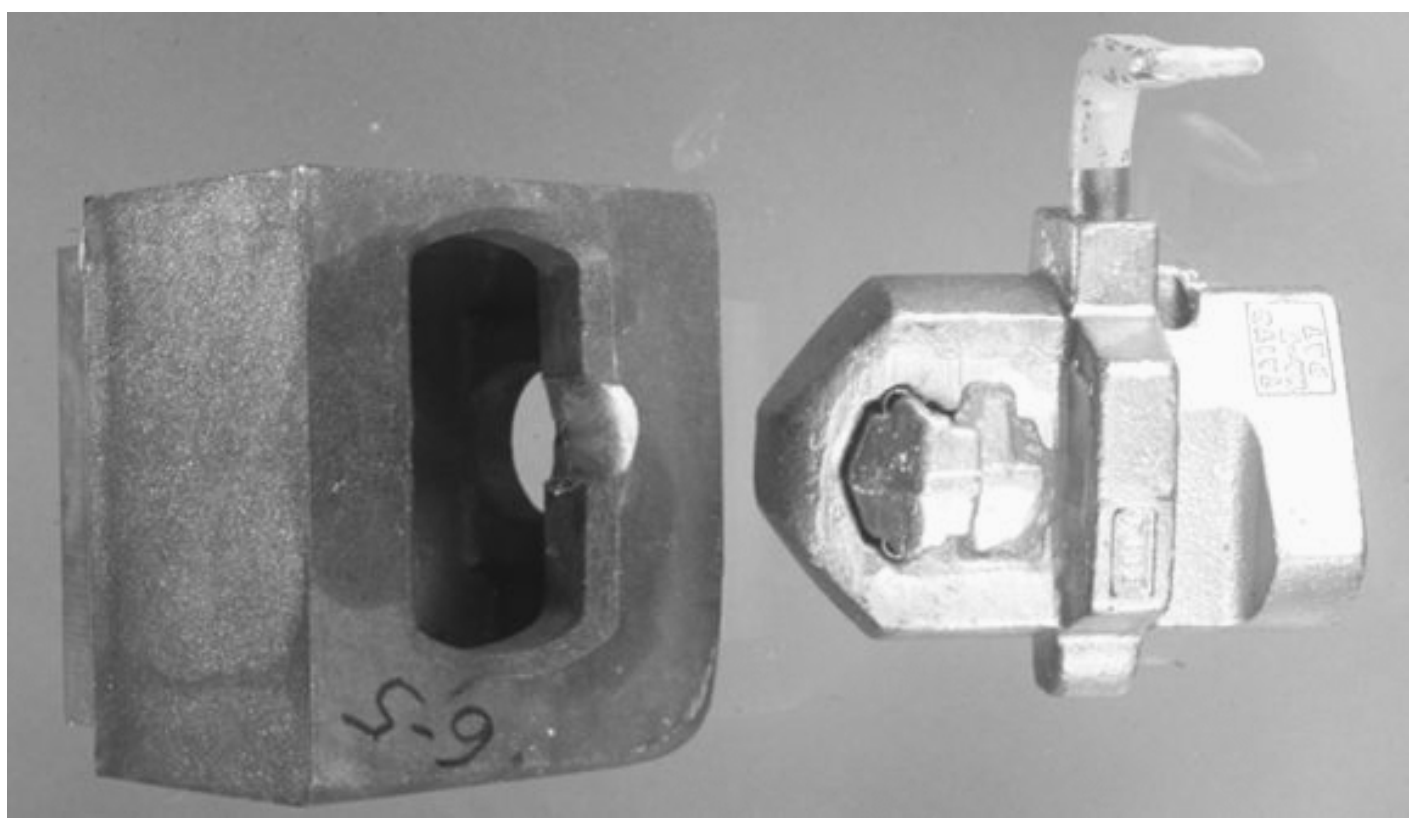

Figure 5.7 Shearing Failure of Corner Fitting by Latch Lock

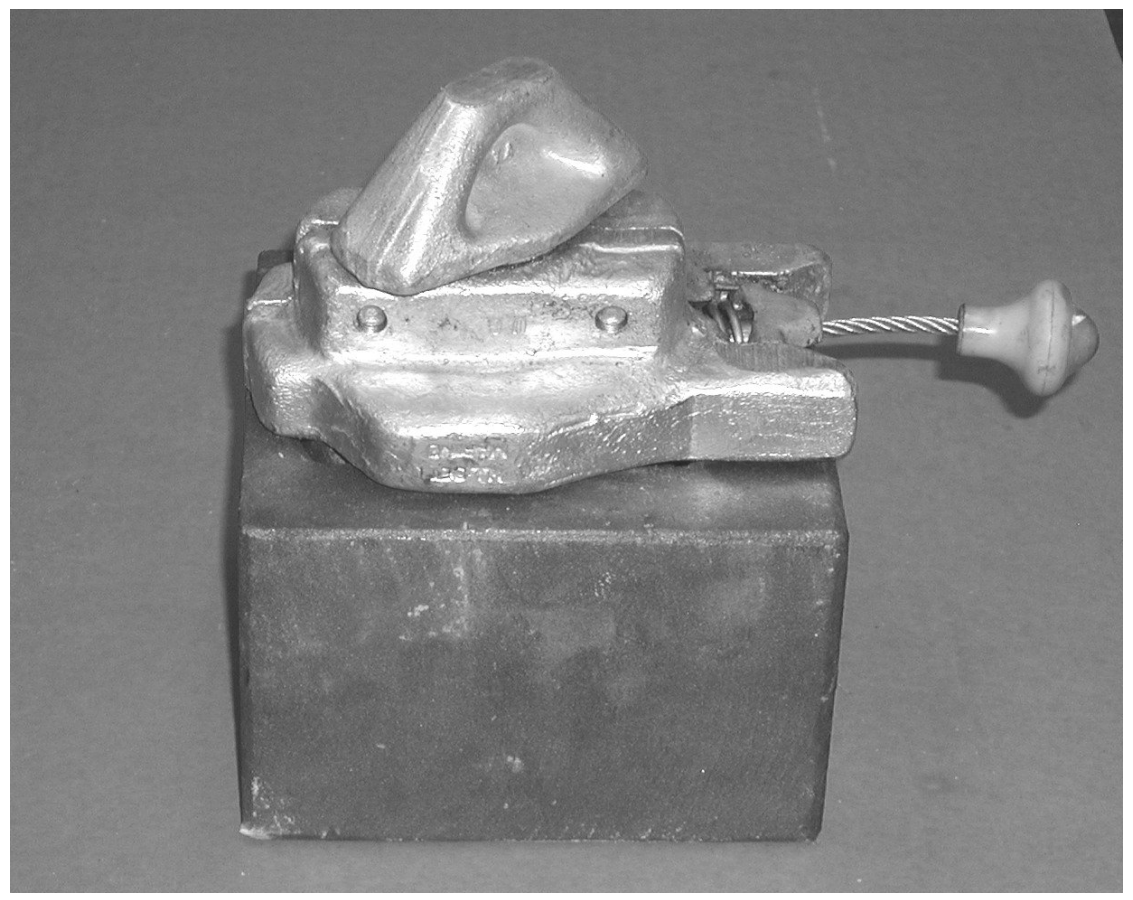

Figure 5.8 Specimen ASM-T-N after Compression Test 


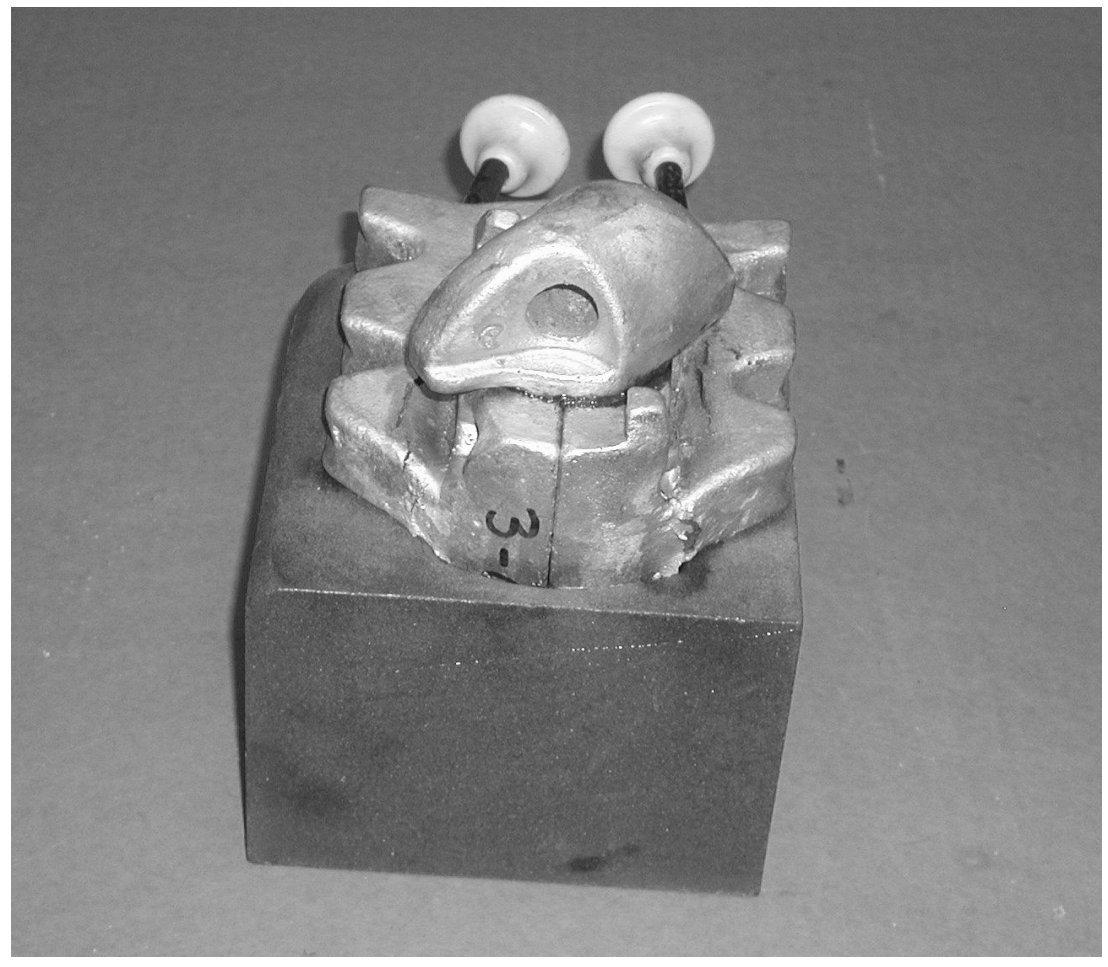

Figure 5.9 Specimen CON-T-N after Compression Test (Note: twistlock depressed into corner fitting.) 


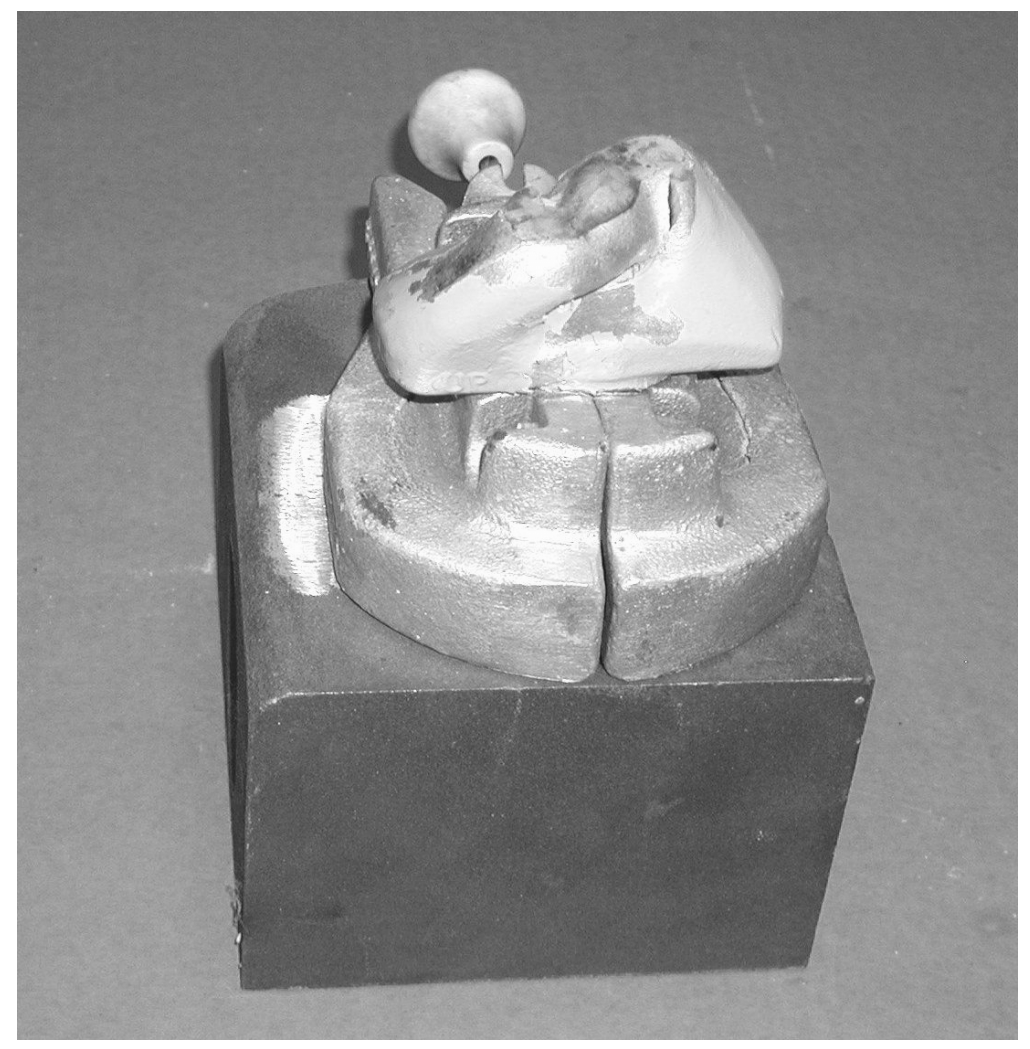

Figure 5.10 Specimen P\&H-T-N after Compression Test (Note: cracks in intermediate plate)

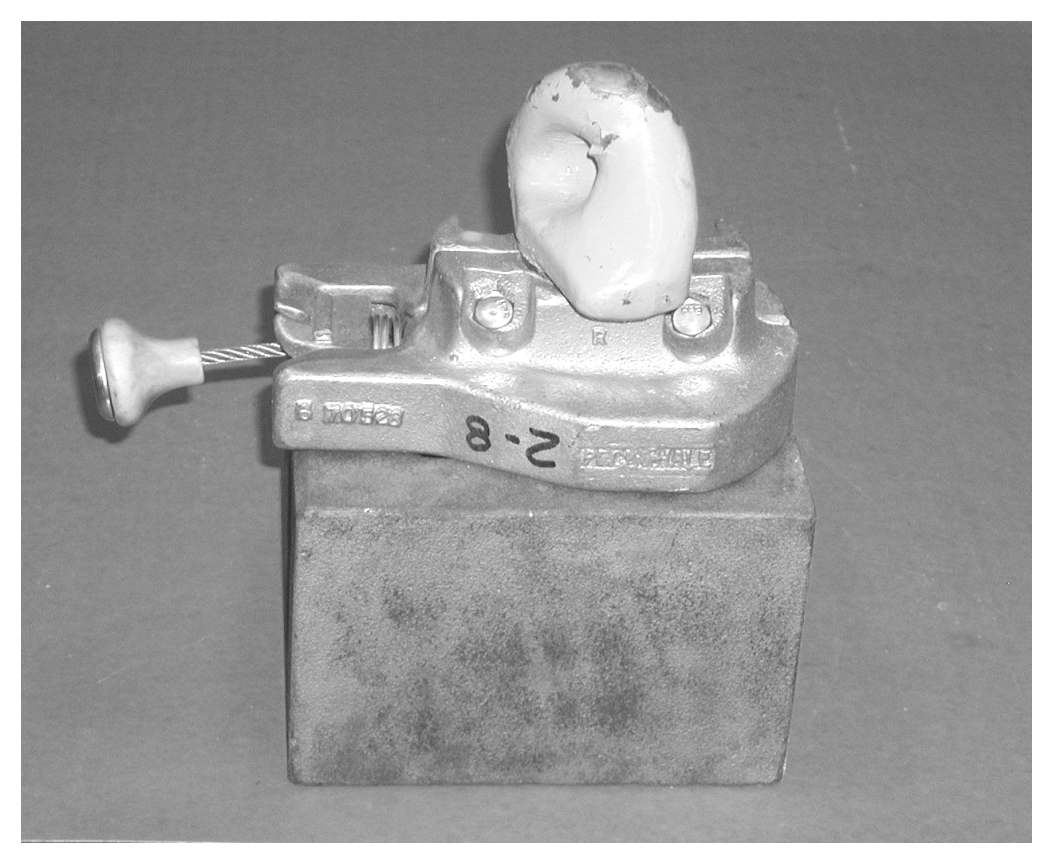

Figure 5.11 Specimen P\&H-T-N after Compression Test (Second Test) 


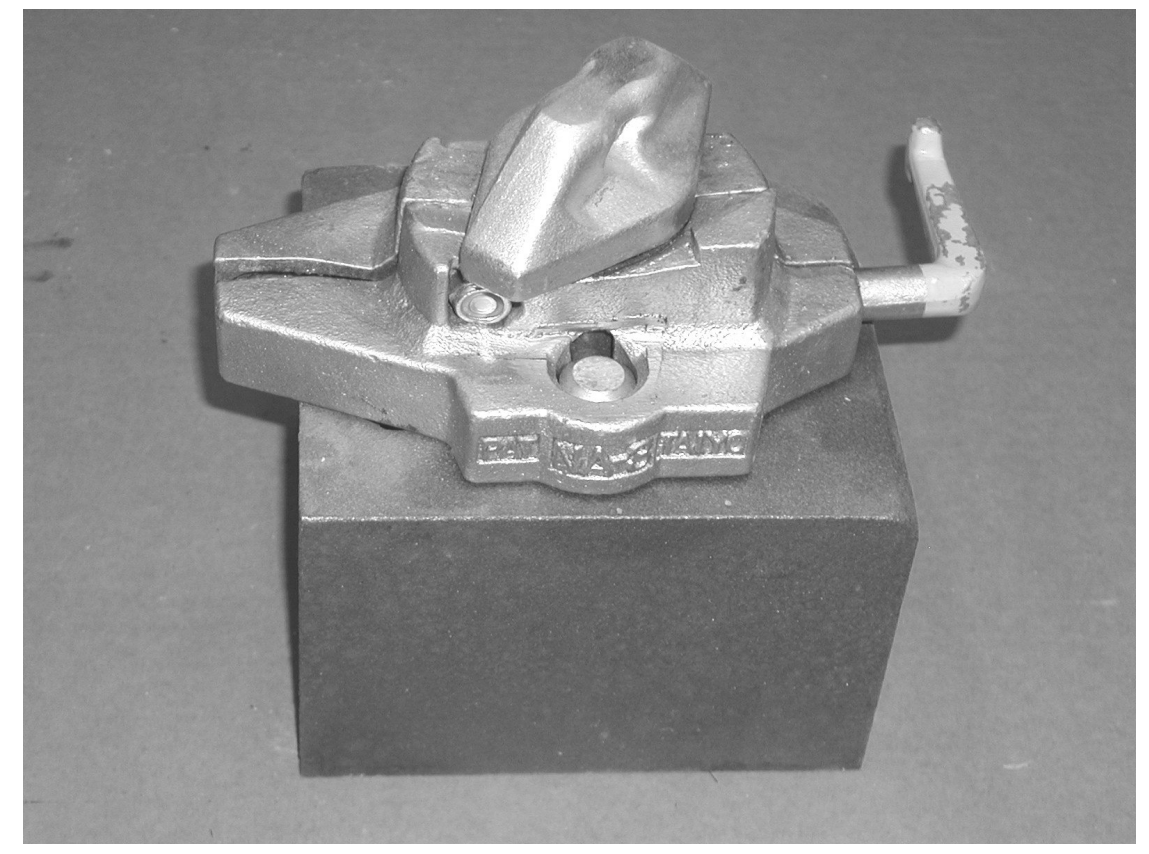

Figure 5.12 Specimen TYS-T-N after Compression Test (Note: spreading of intermediate plate at center)

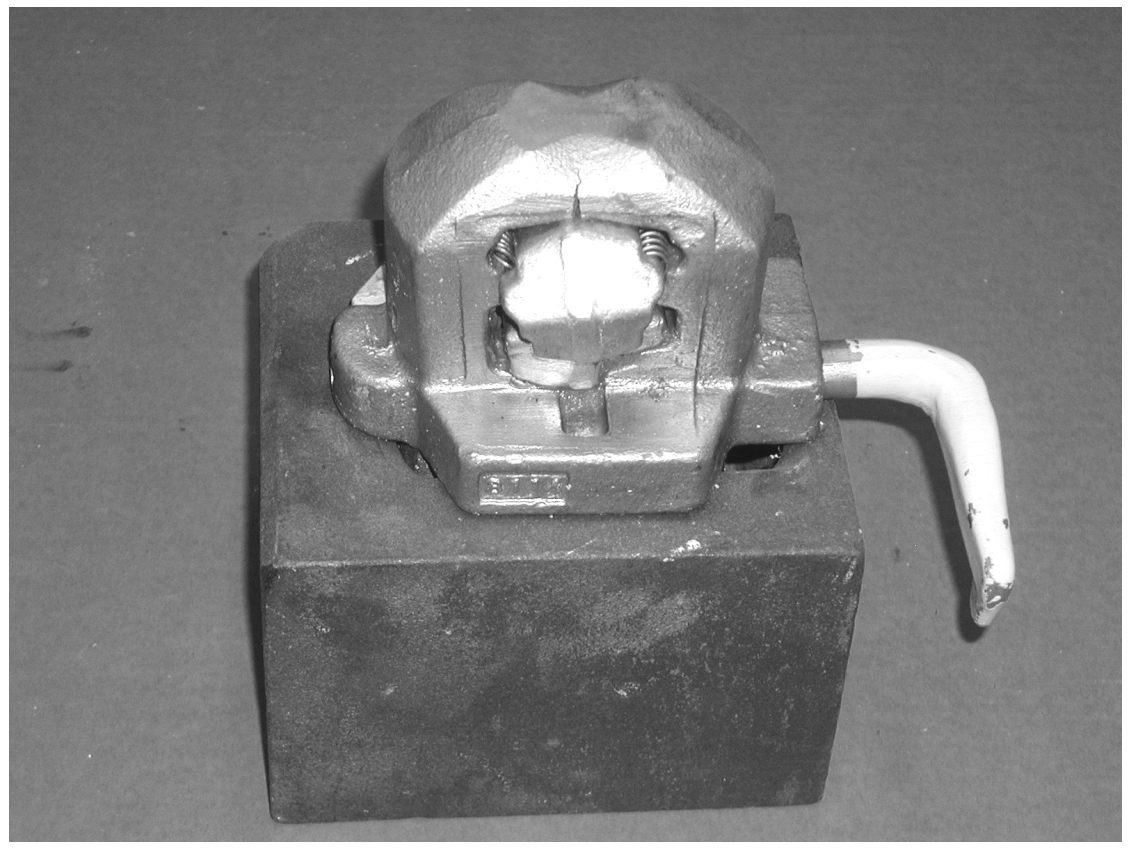

Figure 5.13 Specimen TYS-L-N after Compression Test (Note: cracking at top center of cone) 


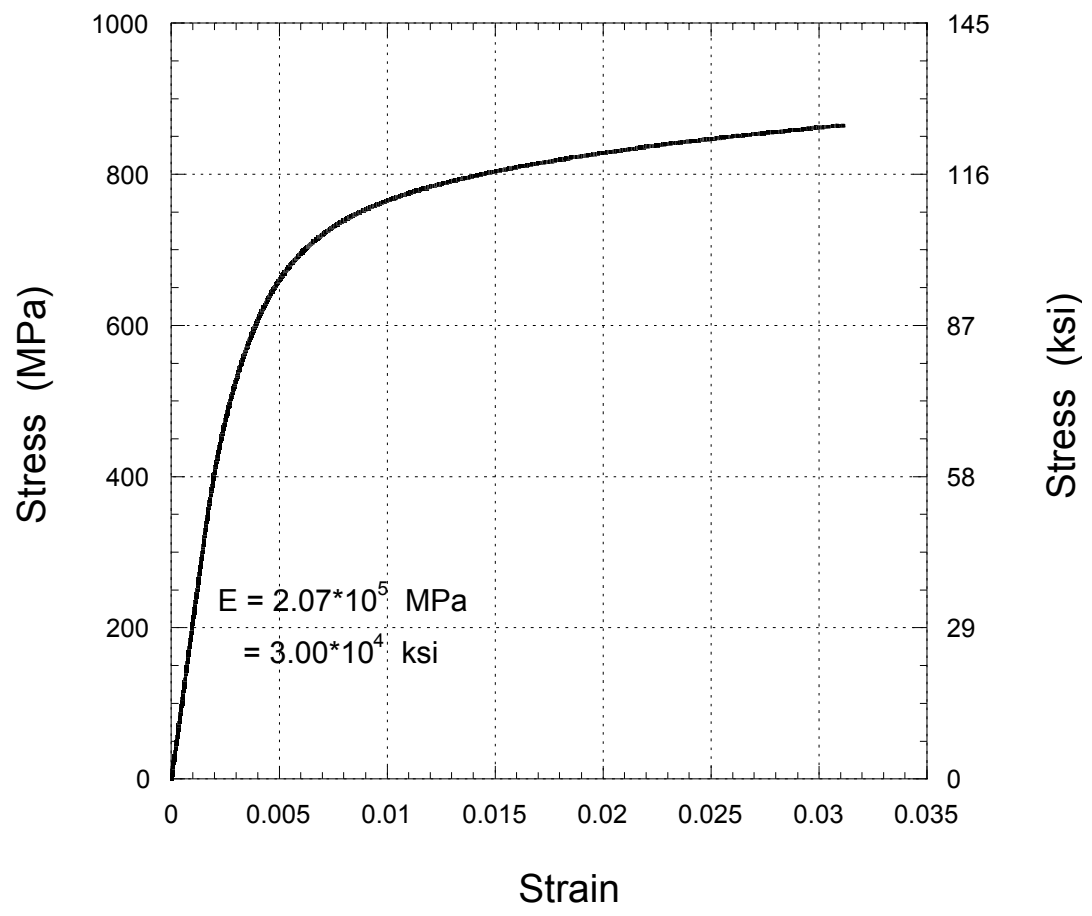

Figure 5.14 Stress-Strain Curve for ASM-T-N (First Specimen)

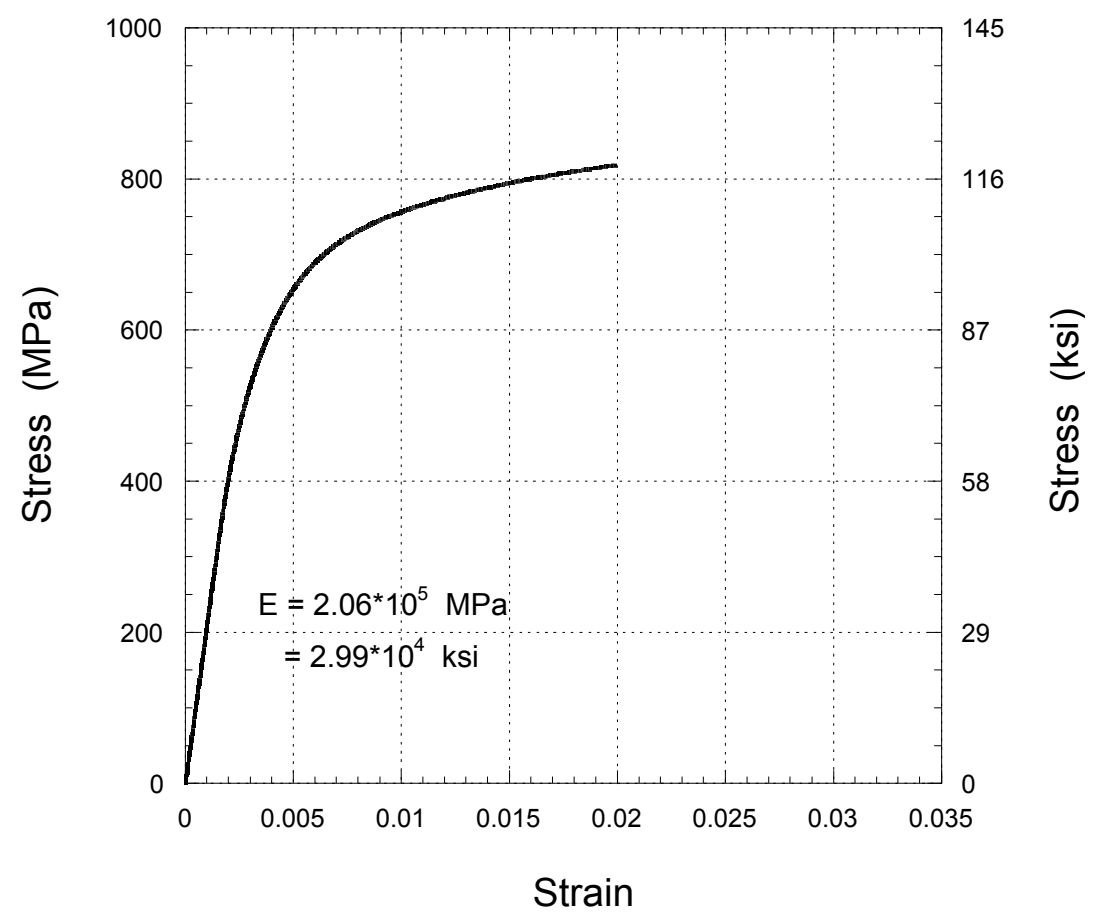

Figure 5.15 Stress-Strain Curve for ASM-T-N (Second Specimen) 


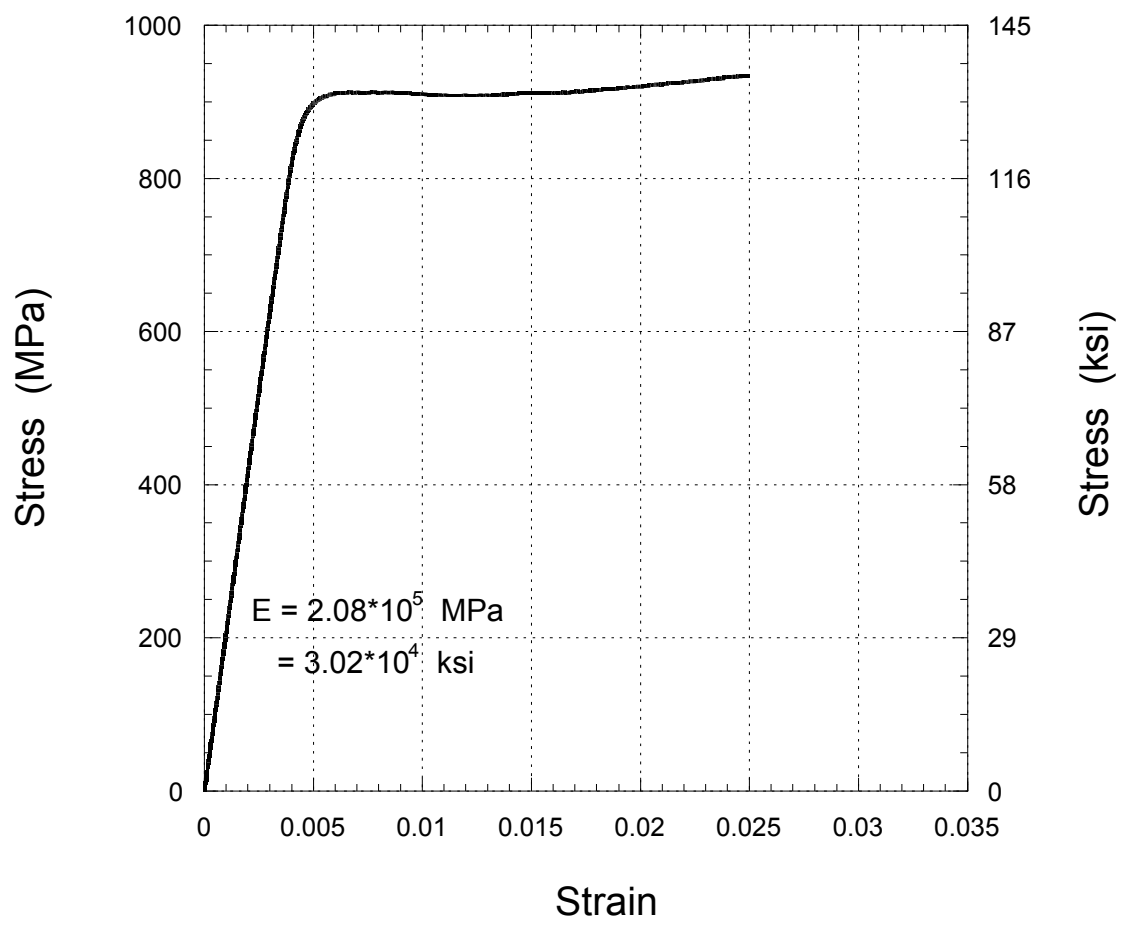

Figure 5.16 Stress-Strain Curve for CON-T-N (First Specimen)

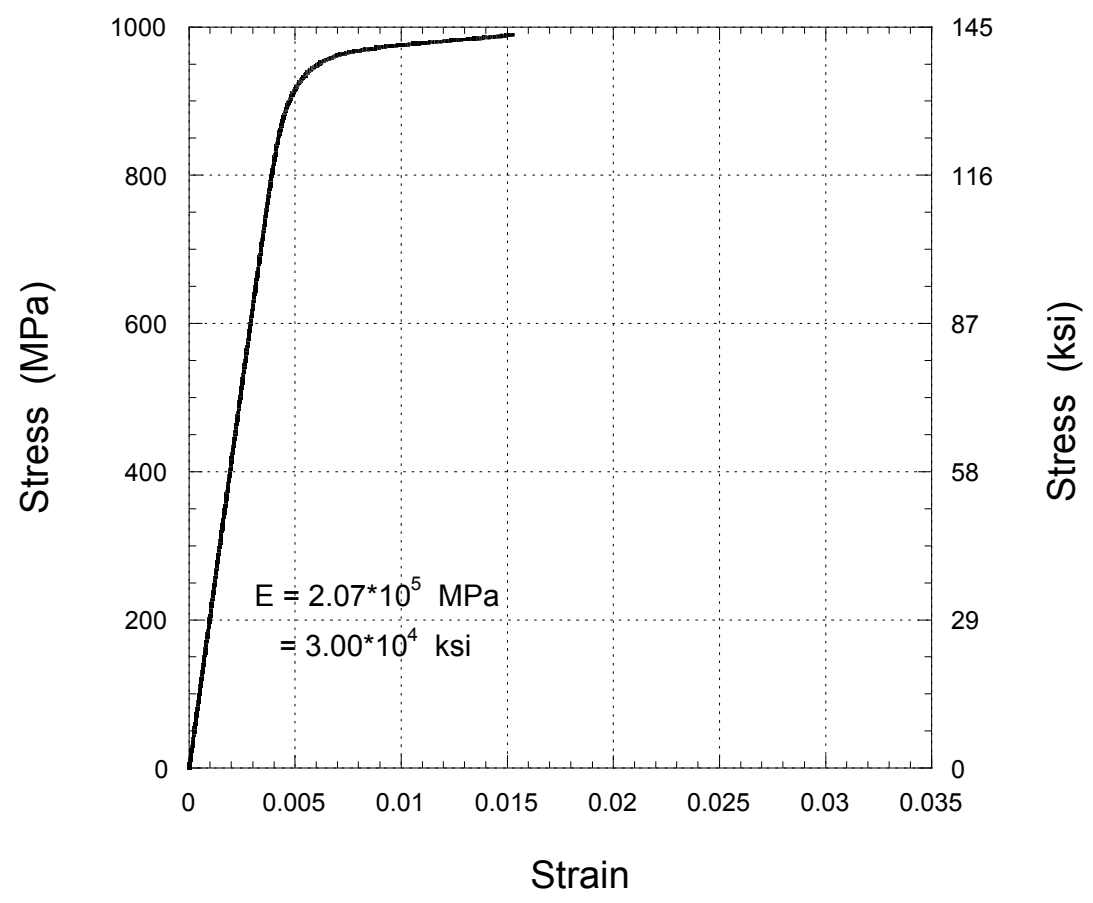

Figure 5.17 Stress-Strain Curve for CON-T-N (Second Specimen) 


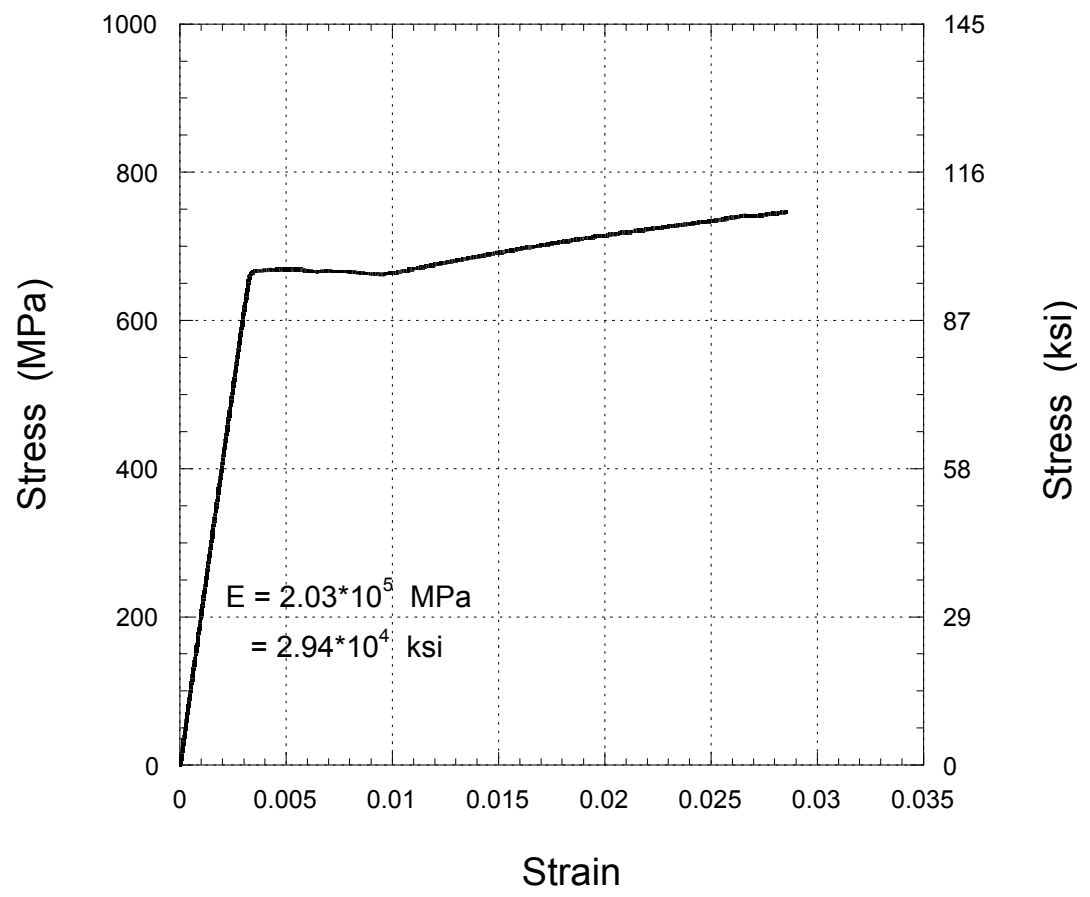

Figure 5.18 Stress-Strain Curve for P\&H-T-N (First Specimen)

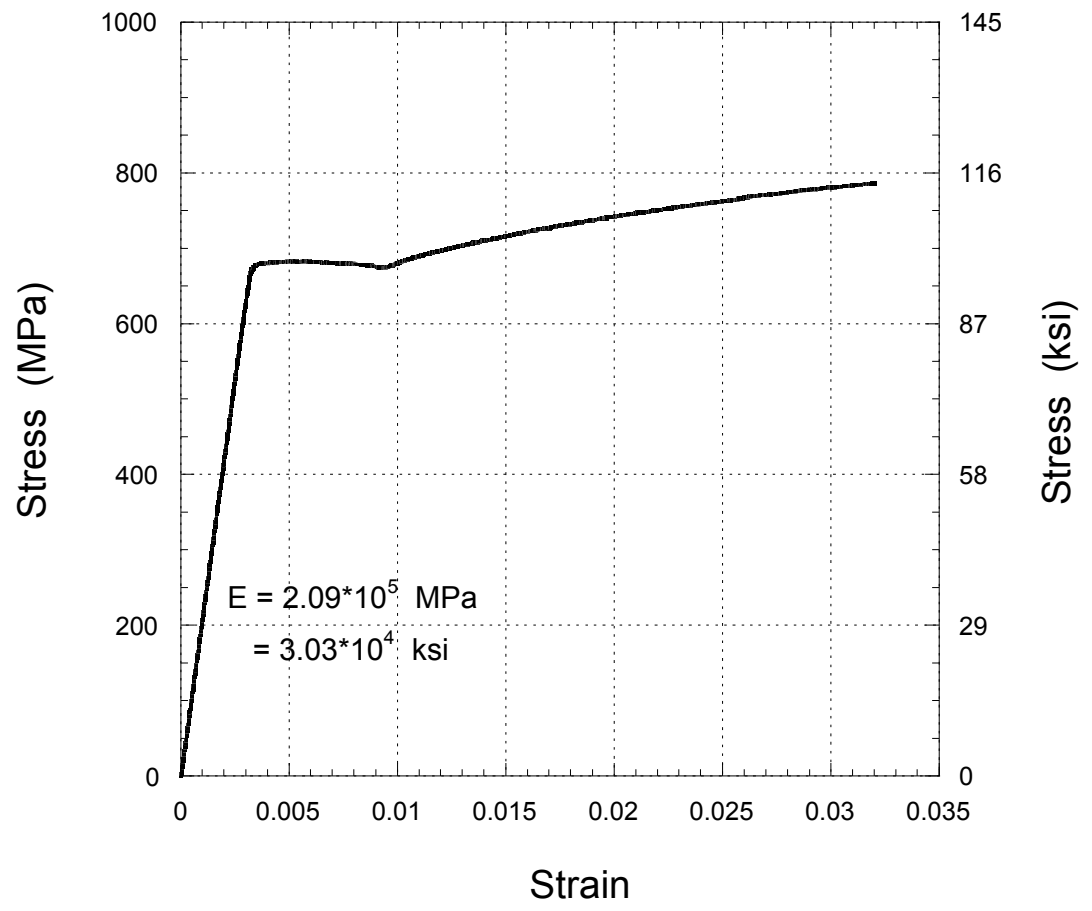

Figure 5.19 Stress-Strain Curve for P\&H-T-N (Second Specimen) 


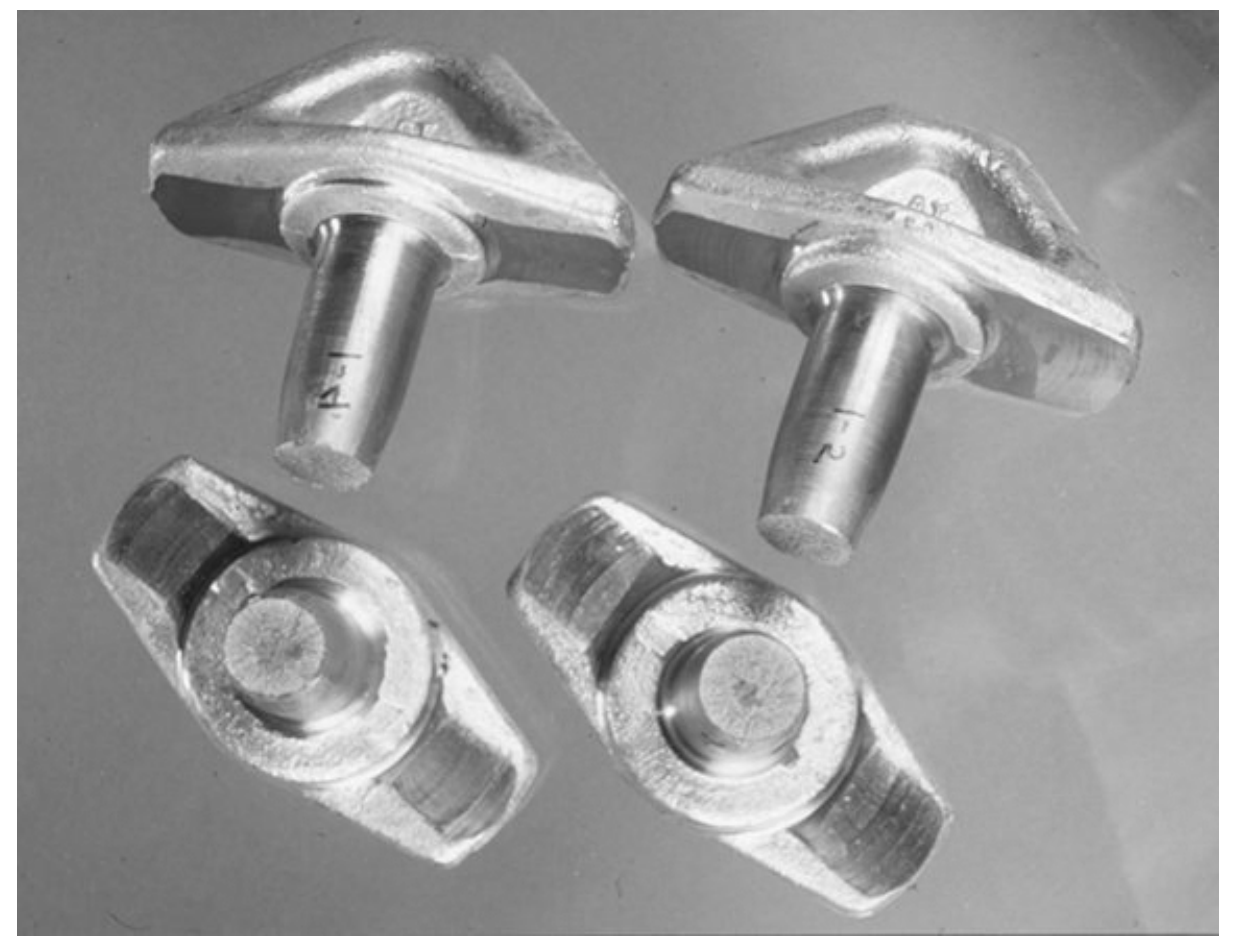

Figure 5.20 Brittle Failure of Tensile Test Specimen (ASM-T-N)

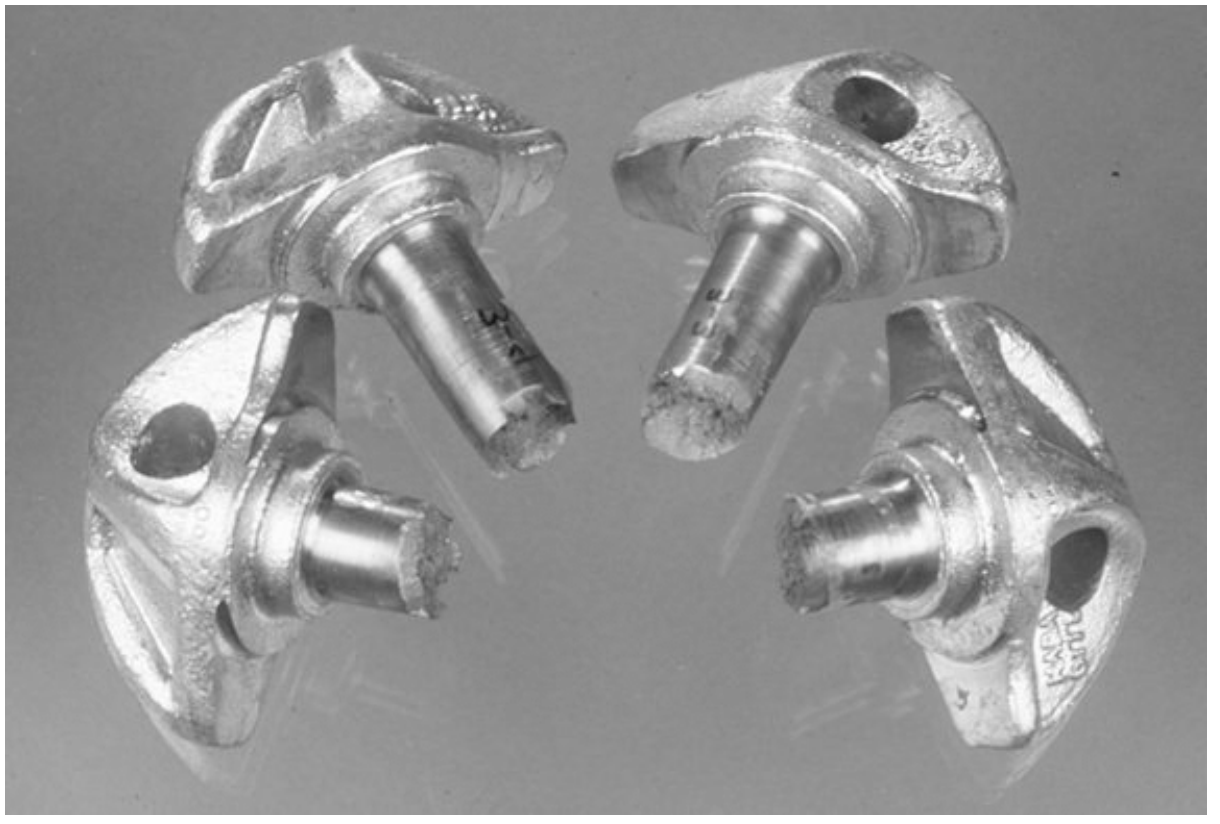

Figure 5.21 Ductile-Shear Failure of Tensile Test specimen (CON-T-N) 


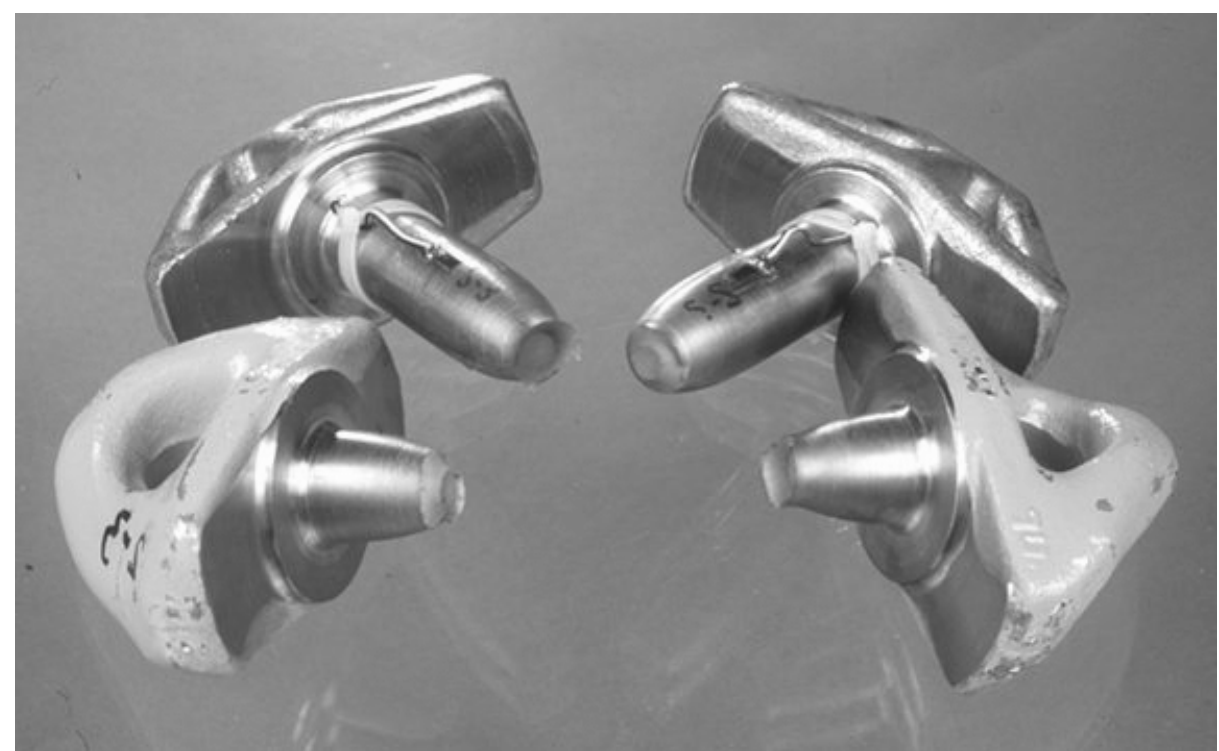

Figure 5.22 Ductile Failure of Tensile Test specimen (P\&H-T-N) 


\subsection{CONCLUSIONS AND RECOMMENDATIONS}

\subsection{Conclusions}

At the request of the Occupational Safety and Health Administration (OSHA), the National Institute of Standards and Technology (NIST) carried out an experimental program to evaluate the strength characteristics of interbox connectors for intermodal containers. New semi-automatic twistlocks from four different manufacturers and new latch locks from one manufacturer were included in the program. To gain information on wearing and aging effects on the strength, used twistlocks from two different manufacturers were also tested.

Twistlock shafts were tested in tension without corner fittings. In addition, assemblies of connectors with corner fittings were tested in tension and compression. The stress-strain relationships of twistlock shaft materials were determined from tensile strength tests on machined twistlock shafts. Load bearing areas of twistlocks and latch locks on the top and bottom corner fittings were measured. These values were compared with the ISO minimum bearing area requirements.

Based on the results of the experimental study presented in this report, the following conclusions are drawn:

1) The maximum load carrying capacity of twistlocks (not considering corner fittings) in direct tension is governed by the fracture strength of the shaft. The tensile load capacity of the shafts ranged from $562 \mathrm{kN}$ (126 $400 \mathrm{lbf}$ ) to $802 \mathrm{kN}$ (180 $300 \mathrm{lbf}$ ).

2) When the top and bottom corner fittings, which are interconnected by a twistlock or a latch lock, are pulled apart, the corner fitting will most likely undergo large deformation. This condition will cause the twistlock cone to disengage from the corner fitting. Furthermore, the cone or the latch will shear the corner fitting at its opening.

3) The maximum tensile loads for the assemblies with twistlocks ranged from $408 \mathrm{kN}(91800 \mathrm{lbf})$ to $710 \mathrm{kN}$ (159 000lbf). For the assembly with a fully extended latch lock, the maximum test load was only $309 \mathrm{kN}$ (69 $500 \mathrm{lbf}$ ). It is important to note that the failure load was reduced significantly when the latch did not extend fully. When the latch was extended to only $57 \%$ of full extension, the maximum tensile load was reduced to $90 \mathrm{kN}$ (20000 lbf).

This study clearly showed that the tensile capacities of the latch lock-corner fitting assemblies are substantially less than those of the twistlock-corner fitting assemblies. This is attributed to the fact that only one latch engages with the corner fitting.

4) When compression load was applied to the top of the connector seated in a corner fitting, no large deformation and/or disfunctioning of twistlocks or latch locks were 
observed up to $445 \mathrm{kN}$ (100 $000 \mathrm{lbf}$ ). The compression load at which twistlocks or latch locks began to disfunction varied from $445 \mathrm{kN}$ (100 $000 \mathrm{lbf}$ ) to $756 \mathrm{kN}$ (170 $000 \mathrm{lbf})$.

5) The measurements of bearing area indicates that the twistlocks would most likely meet the requirement of the ISO Standard 1161, that is, $800 \mathrm{~mm}^{2}\left(1.24 \mathrm{in}^{2}\right)$. With the latch fully extended, however, the bearing area of the latch lock is less than $50 \%$ of this requirement, and is less than required by the ISO 3874 proposed amendment of $600 \mathrm{~mm}^{2}$ $\left(0.93\right.$ in $\left.^{2}\right)$ for one-sided bearing.

The conclusions listed above are based on limited NIST tests of twistlocks and latch locks produced by a limited number of manufacturers. In particular, the corner fittings used in the tests were from one manufacturer. Since corner fittings are manufactured in accordance with the ISO Standard 1161, dimensional variations would be minimal from one manufacturer to another. Thus, the elastic stiffness characteristics of steel corner fittings are about the same regardless of manufacturers. However, the load carrying capacity of the assemblies of connectors and corner fittings would vary depending upon the material strength of corner fittings. The modes of failure of the assemblies may also differ.

\subsection{Recommendations}

1) At present (year 2000), only one requirement is specified in the current ISO standards related to interbox connectors, i.e., the load bearing area of the connector on the corner fitting. This study showed that the tensile capacity of the connection between two vertically joined containers is governed by the strength of the connector-corner fitting assembly. The assembly strength is strongly related to the bearing area of the cone of the connector on the corner fitting. Based on these observations, it is strongly recommended that ISO standards be developed to cover design, manufacturing, testing and standards practice on use of interbox connectors in lifting.

2) A limited number of used connectors were tested. In order to attain reliable data on the bearing area of connectors in service, additional measurements of the bearing area between connector and corner fitting should be made for various types of connectors. 


\subsection{REFERENCES}

1. International Organization for Standardization, "ISO Standard 1161-Series 1 Freight Containers-Corner Fittings-Specification," Fourth Edition, 1984-12-15.

2. International Organization for Standardization, "ISO Standard 1496-1-Series 1 Freight Containers-Specification and Testing," Fifth Edition, 1990-08-15.

3. Annual Book of ASTM Standards, Vol. 01.04, "ASTM A 370-99a Standard Test Methods and Definitions for Mechanical Testing of Steel Products," 1999.

4. Anderson, L.D., "Container Lashing," Swedish National Testing and Research Institute, SP Report 1997:22, 1997.

5. International Organization for Standardization, "ISO Standard 3874-Series 1 Freight Containers-Handling and Securing," Fourth Edition, 1988-08-01. 